NBER WORKING PAPER SERIES

\title{
CROSS-NATIONAL EVIDENCE ON GENERIC PHARMACEUTICALS: PHARMACY VS. PHYSICIAN-DRIVEN MARKETS
}

\author{
Patricia M. Danzon \\ Michael F. Furukawa \\ Working Paper 17226 \\ http://www.nber.org/papers/w17226
NATIONAL BUREAU OF ECONOMIC RESEARCH
1050 Massachusetts Avenue
Cambridge, MA 02138 \\ July 2011
}

Earlier versions of this paper were presented at the 2010 American Society of Health Economics meetings and the 2009 Harvard Law School conference on Legal and Regulatory Issues in Pharmaceutical Research and Development. This research was supported in part by the Merck Foundation Program on Pharmaceutical Policy Issues to the University of Pennsylvania. The analysis is based on data obtained under license from the IMS Health Incorporated MIDAS ${ }^{\mathrm{TM}}$ database. We would like to thank IMS Health and Pfizer Inc. for making the data available. The opinions expressed are those of the authors and do not necessarily reflect the opinions of the research sponsors, IMS Health or the National Bureau of Economic Research. We are responsible for all conclusions and any errors.

NBER working papers are circulated for discussion and comment purposes. They have not been peerreviewed or been subject to the review by the NBER Board of Directors that accompanies official NBER publications.

(C) 2011 by Patricia M. Danzon and Michael F. Furukawa. All rights reserved. Short sections of text, not to exceed two paragraphs, may be quoted without explicit permission provided that full credit, including (C) notice, is given to the source. 
Cross-National Evidence on Generic Pharmaceuticals: Pharmacy vs. Physician-Driven Markets Patricia M. Danzon and Michael F. Furukawa

NBER Working Paper No. 17226

July 2011

JEL No. I11,I18,K2,L5,L65

\begin{abstract}
This paper examines the role of regulation and competition in generic markets. Generics offer large potential savings to payers and consumers of pharmaceuticals. Whether the potential savings are realized depends on the extent of generic entry and uptake and the level of generic prices. In the U.S., the regulatory, legal and incentive structures encourage prompt entry, aggressive price competition and patient switching to generics. Key features are that pharmacists are authorized and incentivized to switch patients to cheap generics. By contrast, in many other high and middle income countries, generics traditionally competed on brand rather than price because physicians rather than pharmacies are the decision-makers. Physician-driven generic markets tend to have higher generic prices and may have lower generic uptake, depending on regulations and incentives.

Using IMS data to analyze generic markets in the U.S., Canada, France, Germany, U.K., Italy, Spain, Japan, Australia, Mexico, Chile, Brazil over the period 1998-2009, we estimate a three-equation model for number of generic entrants, generic prices and generic volume shares. We find little effect of originator defense strategies, significant differences between unbranded and unbranded generics, variation across countries in volume response to prices. Policy changes adopted to stimulate generic uptake and reduce generic prices have been successful in some E.U. countries.
\end{abstract}

\author{
Patricia M. Danzon \\ Health Care Management Department \\ The Wharton School \\ University of Pennsylvania \\ 3641 Locust Walk \\ Philadelphia, PA 19104 \\ and NBER \\ danzon@wharton.upenn.edu \\ Michael F. Furukawa \\ Department of Information Systems \\ W.P. Carey School of Business \\ Arizona State University \\ PO Box 874606 \\ Tempe, AZ 85287-4606 \\ Michael.Furukawa@asu.edu
}




\section{Introduction}

Pharmaceutical markets in the U.S. are characterized by relatively high prices while drugs are on patent, followed by rapid generic entry and low generic prices once patents expire. In 2009, generics accounted for 74.5 percent of prescriptions (Berndt and Aitken, 2010) but only about 20 percent of sales, because generic erosion is rapid and generic prices are low, relative to originator prices in the U.S. By contrast, generic penetration is slower and generic prices are higher, both absolutely and relative to originator prices, in many other countries, implying only modest savings from generics for payers and patients. These modest generic savings are prima facie surprising. Post-patent entry should in theory be profitable for generic producers and appealing for customers, because generics can largely free-ride on the R\&D and informational investments made by originator firms, thereby realizing much lower cost structures. Expiry of patent barriers to entry also makes generic markets potentially more competitive than originator markets.

This paper argues that these cross-national differences in generic shares and prices reflect differences in regulatory and reimbursement policies that drive countries to have either pharmacy-driven or physician-driven generic markets. The U.S. is a prototypical pharmacydriven generic market. Pharmacists are the key decision-maker for generics, because they are legally authorized to substitute any substitutable (AB-rated) generic unless the physician explicitly requires the brand, which is rare. U.S. pharmacies have financial incentives to prefer cheaper generics and brand is irrelevant for substitutable generics that by regulation are certified to be bioequivalent to the originator. Generics are therefore unbranded and compete on price for the business of highly-price conscious pharmacies. Centralized purchasing by large chain pharmacies has intensified generic competition in the U.S. Tiered co-payment structures have encouraged patients to accept generics. However, pharmacies decide which generic to dispense and patients, payers/PBMs and physicians usually play no role in choosing one generic manufacturer over another (except for drugs dispensed through the mail, for which the PBMs operate their own pharmacies). The U.K. and Canada resemble the U.S. pharmacy-driven generic model in some respects, but with important differences, notably in Canada which regulates generic prices rather than relying on competition.

By contrast, the regulation/reimbursement structure for generics in many other countries has traditionally given less authority and fewer or even perverse incentives to pharmacies. In 
particular, substitution was only permitted if the physician prescribed by chemical name (which is uncommon except in the U.K.), and pharmacy dispensing fees that increased with the price of the drug discouraged substitution of cheaper products, even if permitted. In markets where pharmacists are either not authorized or incentivized to substitute, physicians prescribe generics and originators by brand name and have little incentive to be price-sensitive (unless they are personally at risk for drug costs). Generic companies therefore market "branded generics" that compete on brand rather than price. Among major E.U. markets, France, Spain, Italy and Germany were traditionally physician-driven, branded generic markets. Latin America also has physician-driven, branded generic markets, with the added feature that many of these branded generics are "similar" (have not met bioequivalence standards to the originator) and are therefore of uncertain quality. Our basic hypothesis is that branded generics in physician-driven generic markets will tend to be higher priced and have lower market shares than unbranded generics in pharmacy-driven generic markets.

During the 2000's, all the major E.U. countries adopted policy changes to reduce prices and/or increase generic uptake and thereby realize generic savings. In 1989, Germany adopted generic reference pricing to encourage competition in off-patent products and expanded the system to include on-patent products in 2005. France, Italy and Spain adopted variants of generic reference pricing in the early 2000’s. ${ }^{1}$ Although such RP systems usually induce originators to cut prices to the RP, whether they create strong incentives for generic competition below the initial RP depends critically on rules and incentives for pharmacy substitution. Most of these countries have also expanded authorization for pharmacy substitution and modified dispensing fees to incentivize generic use. Since 2007, German sickness funds have contracted directly with generic companies, using competitive bidding to drive price competition and capture the resulting savings for payers.

Latin American markets were also traditionally physician-driven, branded generic markets, but with many "similares” or copy products that were launched prior to originator patent expiry and were not required to meet bioequivalence standards. Brazil and Mexico have established regulatory frameworks to authorize true, bioequivalent generics, but many similares remain on the market. Pharmacy substitution is usually not legally authorized in countries where

\footnotetext{
${ }^{1}$ Under generic reference pricing, the payer sets a single reference price (RP) as a maximum reimbursement for all generically equivalent products, leaving the patient to pay any excess of the manufacturer's price over the RP.
} 
generics are not required to be bioequivalent. In practice, patients often purchase drugs without a prescription, in which case pharmacists may advise on substitution. Because generic quality is uncertain, brand plays an important role in generic choice. Thus although patients generally pay out-of-pocket for outpatient drugs and are presumably price sensitive, quality uncertainty leads to competition on brand and undermines competition on price.

In Japan, physicians and hospitals traditionally dispensed the drugs that they prescribed and captured any margin between a drug's reimbursement price and its market price (or acquisition cost). Branded generics were the norm. Their incentive was to maintain the reimbursement price as high as possible, to enable discounting of the market price below the reimbursement price, to increase the margin realized by the dispensing providers. Savings accrued to payers only with a lag, as reimbursement prices were adjusted based on market prices every two years. Unbranded generics had little presence in Japan until recent reforms.

This paper examines the performance of generic markets in 10 countries (the U.S., the U.K., Germany, France and Spain, Italy, Japan, Canada, Brazil and Mexico) over the period 1998-2009. Our analysis draws on data from IMS Health Inc. on the universe of drug sales in these countries. Our data permit both between-country comparison of branded vs. unbranded generic markets and within-country comparison over time, to estimate effects of the policy changes. We estimate a model for three dimensions of generic markets: any entry and number of generic manufacturers; generic prices, relative to baseline originator prices; and generic volume share. We examine how each of these dimensions of generic markets changed over time in response to policy changes.

We also examine the effects on generic markets of originator defense strategies, specifically, launch of new licensed brand products (co-branding) or new formulations prior to patent expiry. Theory and prior evidence suggest that co-branding may be effective in physiciandriven, branded generic markets (for Italy, see Pammoli et al. 2002; for Germany, see Appelt, 2009); however, such strategies are less likely to be effective in pharmacy-driven, unbranded generics market. Launching new formulations prior to patent expiry on older formulations may be a rational strategy in both market types, depending on reimbursement rules. Originator strategies to deter generic entry have been the focus of the E.U. Generics Inquiry.

Our empirical evidence confirms that generic price competition is greater in pharmacydriven markets than in physician-driven markets, provided that pharmacies face financial 
incentives to prefer cheaper products. Branded generics, which predominate in physician-driven markets, are less price competitive than unbranded generics that predominate in pharmacy-driven markets, as predicted. Our results confirm previous evidence that generic entry is related to market size; however, differences across countries in number of generic competitors is not explained by overall market size, plausibly because the extent of price competition, cost structures and profit margins also differ. We find little evidence that originator defense strategies are successful on average, except that launch of delayed release formulations does deter generic penetration in the U.S. Recent changes in generic regimes in four previously physician-driven, branded generic markets of the E.U. (Spain, France, Italy and Germany) have had significant effects, with unbranded generics gaining share. However, these countries still lag the U.S. and U.K. in speed and extent of generic penetration.

\section{Generic Regulation and Reimbursement}

Generic entry is constrained in all countries that are members of the World Trade Organization (WTO) by patents and regulatory protections of innovator products. Although all WTO countries must recognize a 20-year product patent term, effective patent life for pharmaceuticals is typically shorter but differs across countries (Grabowski and Kyle, 2007). Most countries provide for some patent term restoration to compensate for time lost during R\&D, and a data exclusivity period during which generics may not reference the originator data for regulatory approval. Patents may also be challenged prior to expiry, and this is increasingly common in the U.S. The originator's effective patent life post launch is the net result of all these factors.

Patents may be challenged in any country, but the U.S. is unique in rewarding successful challenges, by granting 180-day market exclusivity to the first generic to successfully challenge the originator patents (a paragraph IV certification). ${ }^{2}$ During this 180 days, the originator may market an authorized generic (licensed under the originator's NDA), but no other ANDAapproved generics can enter. These paragraph IV and associated 180-day exclusivities have reportedly become increasingly common since the late 1990's, which is expected to result in

\footnotetext{
${ }^{2}$ The 1984 Waxman-Hatch Act's Abbreviated New Drug Application (ANDA) process permits generic approval with evidence of bioequivalence, once the originator's patents and other exclusivities have expired or been successfully challenged.
} 
higher generic prices during the first two quarters post launch in the U.S. Greater use of paragraph IV may also result in earlier generic entry over time in the U.S., unless it is offset by increased originator use of mechanisms for patent and exclusivity extensions.

In addition to patent and data exclusivity provisions, the incentives for generic entry and generic price competition depend on regulatory rules affecting generic competition and reimbursement, including rules government pharmacists’ authority to substitute generics; reimbursement incentives for substitution; whether generic prices are regulated or competitively set; and patients' incentives to accept generics, through co-payment structures. The tiered copayment structure in the US offers patients a larger financial incentive to accept generics than in any other country.

Table 1 summarizes regulatory and reimbursement characteristics of our sample countries. This is an oversimplification of the complex regimes and changes over time in each country. ${ }^{3}$ As a rough characterization, we assume that the U.S., the U.K., and Canada are primarily pharmacy-driven generics markets, and physician-driven markets include France, Germany, Italy, and Spain at the start of our period, plus Japan, Brazil, and Mexico.

Most countries implemented changes in the 2000’s. France, Germany, Italy, and Spain implemented multiple policy changes to stimulate generic uptake and/or reduce prices. The U.K. changed its rules for setting generic reimbursement in 2005. Brazil and Mexico encouraged bioequivalence testing and the growth of unbranded generics. The U.S. experienced some growth in paragraph IV challenges, and the 2003 Medicare Modernization Act reduced the incentives for originators to list late patents by permitting only one 30-month stay per molecule. ${ }^{4}$ Some Canadian provinces reduced the regulated prices on generics, and other changes were adopted in 2010, after our observation period. Our empirical analysis tests for effects of these changes in each country.

\section{Previous Literature}

Early studies of generic entry and price competition focused on the U.S. Models of number of entrants have consistently found that generic entry is related to market size (for example, Scott Morton, 1999; Saha et al., 2006) and that generic prices are inversely related to

\footnotetext{
${ }^{3}$ More detail is reported in an Appendix available upon request from the corresponding author.

${ }^{4}$ When a generic company challenges an originator patent, the originator may obtain an injunction for up to 30 months or the resolution of the litigation, whichever occurs first.
} 
number of generic competitors in the U.S. (Grabowski and Vernon, 1992; Saha et al., 2006). Most previous studies do not address the role of pharmacies as key decision-makers in U.S. generic markets and the effects of pharmacy-driven markets on the nature of competition. Several papers (for example, Scott Morton, 2000) hypothesize that originator firms may use promotion to deter generic penetration but find no effects. This is unsurprising in the context where pharmacy substitution is the norm, such that detailing to persuade physicians to choose a particular brand does not assure that the originator product is dispensed. In such markets, originator advertising generally declines and ultimately ceases as patent expiration approaches. ${ }^{5}$ Reiffen and Ward (2005) estimate a structural model of generic entry and prices using data from the early 1990s.

Several recent papers have examined generic uptake in other countries. Hollis (2003) reports on anti-competitive effects of strategic licensing of brand-controlled “pseudo-generics” in Canada, which are found to deter generic entry. Magazzini et al. (2004) examine generic entry in the U.S., the U.K., Germany and France using sales data from July 1987-December 1998 on major molecules with patent expiry 1986-1996. Using a Tobit estimator applied to pooled panel data for the four countries, they conclude that market share of licensed products (defined as products launched within 3 years of patent expiry) is negatively related to unbranded generic market share whereas number of different brand names has a positive effect. Possible reasons for these apparently contradictory findings are not explored. ${ }^{6}$ Appelt (2009) provides evidence of originator licensing strategies prior to patent expiry and branded generics' use of trade marks to enhance brand competition in Germany's branded generic market. Hudson (2000) examines generic entry and erosion of brand shares in four markets (U.S., U.K., Germany and Japan) using data from the early 1990's which predates the more recent growth in generic erosion in the U.S. and pro-generic policy changes in other countries. Moreno-Torres et al. (2009) provide detailed evidence on generic entry in Spain. Ghislandi et al. (2005) and Garattini and Ghislandi (2006) discuss recent changes in Italy. Kanavos et al. (2008) and Puig-Junoy (2010) discuss European price regulation and its impact on generic competition.

\footnotetext{
${ }^{5}$ Ellison and Ellison (2011) find weak evidence for pre-patent expiry use of promotion to deter generic entry by medium-sized incumbents, using data from 1986-1992, which predate the growth of payer strategies to encourage pharmacy substitution and generic uptake by patients.

${ }^{6}$ They regress market share of unbranded drugs on lagged market share of licensed products in an uncensored Tobit model that includes markets with no generics. The negative coefficient on licensed products may be dominated by the observations with zero generic share (for which the relationship is necessarily negative), and it is unclear whether it would hold in the subset of market with generic entry.
} 
Our paper adds to these previous studies by providing a consistent analysis and comparison across 10 different countries and over a more recent time period that includes experience after the recent reforms in several countries. Our approach is also the first to focus on the importance of pharmacy substitution and pharmacy incentives in creating pharmacy-driven rather than physician-driven generic markets, and the resulting distinction between competition focused on price vs. brand.

\section{Data}

The data for this study are from the IMS MIDAS database of quarterly sales of all drugs over the period 1998-2009 in 10 countries, including the major E.U. markets, two major Latin American markets, the U.S., Canada and Japan. Within this universe of products, we define the sample of molecules potentially subject to generic entry as molecules with global age (years since first global launch of the molecule) between 8 and 20 years. This age window was selected based on the assumption that product patents are filed at roughly the same date in all countries, that R\&D (discovery, preclinical and clinical trials, and regulatory review) typically absorbs at least 8 of the 20 year patent term, and that most countries offer patent extensions or supplementary protection certificates for up to 5 years to compensate for this loss. ${ }^{7}$ This age range encompasses the ages with greatest generic entry, although entry in most countries spans a longer age range. We define the lag in generic entry of product $\mathrm{i}$ in country $\mathrm{j}$ as months from first originator launch of that product in country j, recognizing that this lag may reflect legal barriers as well as economic factors. ${ }^{8}$

Our analysis focuses on single molecule prescription drugs in the retail pharmacy channel. We exclude combination products, for which global age and hence generic eligibility are ambiguous. We exclude biologics because they are ineligible for the standard abbreviated generic approval procedures in the U.S. and most other countries. ${ }^{9}$ We also excluded miscellaneous therapeutic categories (hospital solutions, diagnostic agents, various) and unusual forms (non-human use, use unknown). IMS assigns each product into one of five license

\footnotetext{
${ }^{7}$ Defining products eligible for generic entry by expiry date of all listed patents is not appropriate, even if we had the data, because generic companies increasingly challenge listed patents prior to their expiry.

${ }^{8}$ Major differences across countries in regulatory and reimbursement barriers to generic entry are described in an Appendix, which is available upon request from the corresponding author.

${ }^{9}$ Abbreviated approval procedures for biosimilars have been outlined in the E.U. and U.S. in the late 2000's. Although a few biosimilars have been launched, their higher regulatory costs and lower substitutability make them very different from chemical generics analyzed here.
} 
categories: originator brand, licensee, branded generic, unbranded generic, or "Patent not assigned" ${ }^{10}$ Our analysis is at the level of the presentation (molecule-form-strength) because pharmacy substitution is authorized only within presentation. All price and sales data are adjusted to 2009 values using country-specific general producer price indexes (PPIs) as the best available measure of input costs. Most analysis is in local currency units, but where prices are converted to U.S. dollars we use 2009 exchange rates.

Although this IMS database is more comprehensive and more detailed than the data used in previous studies, certain limitations must be noted. First, the IMS categorization of generics as branded or unbranded is the best available but may nevertheless be an imperfect indicator for whether products compete primarily on brand or price. Second, the products designated as generics in some countries, notably Brazil and Mexico, include copy products (similares), some of which entered early in the originator life, due to lack -- or weak enforcement -- of product patent regimes, and are not necessarily bioequivalent to the originator drug. ${ }^{11}$ Third, the IMS data do not designate which generics have met bioequivalence tests and hence are more likely to be considered substitutes by physicians, pharmacists and patients than those that lack a bioequivalence certification. Fourth, when a merger occurs between two firms, IMS consolidates their separate data retroactively. Our data may therefore potentially undercount the number of generic competitors, particularly in the earlier years.

\section{Empirical Framework and Methods}

Our descriptive and regression analyses focus on the main determinants of overall generic savings to payers: whether and when generic entry occurs; number of branded and unbranded generic competitors; generic and originator prices; and generic volume shares. The analysis is at the level of the presentation-country-quarter, defined by molecule, four-digit anatomical therapeutic class, formulation and strength, because pharmacy substitution of generics is authorized only between presentations with the same molecule, formulation and strength. We

\footnotetext{
${ }^{10}$ We used the corporation and molecule age to reassign products with Patent Not Assigned into branded generic or unbranded generic status.

${ }^{11}$ We excluded from these calculations the small number of generic launches that reportedly occurred within 5 years of the originator launch, except in countries where such early launch dates are plausible due to late adoption of patent regimes (Brazil, Mexico, Italy, and Spain). For other countries, we reassigned the license status of these implausibly early generics from branded generic to licensed brand and included them as licensees in all other analysis. We also exclude generics for which no originator is present in any year of our data.
} 
estimate a four equation model for: any generic entry for the $\mathrm{i}^{\text {th }}$ presentation in country $\mathrm{j}$ in year t; number of generic firms, conditional on entry; generic or originator price (relative to baseline originator price); and generic volume share:

$$
\begin{aligned}
& G_{i j t}=f_{1}\left(R_{i j t-2} ; D_{i j t-2} ; F_{i j} ; M_{i j} ; Z_{t} ; u_{1 i j t}\right) \\
& N_{i j t}=f_{2}\left(R_{i j t-2} ; D_{i j t-2} ; F_{i j j} ; M_{i j} ; Z_{t} ; u_{2 i j t}\right) \\
& P_{i j t}=g\left(N_{i j t}^{b} ; N_{i j t}{ }^{u} ; F_{i j j} ; M_{i j} ; Z_{t} ; u_{3 i j t}\right) \\
& S_{i j t}=h\left(P_{i j t} ; N_{i j t}^{\text {b. }} ; N_{i j t}{ }^{u} ; F_{i j} ; M_{i j} ; Z_{t} ; u_{4 i j t}\right)
\end{aligned}
$$

where $G_{i j t}$ is an indicator for Any Generic entrant in the presentation-country-year, $N_{i j t}$ is number of generic manufacturers (branded and unbranded), conditional on entry, $\mathrm{P}_{\mathrm{ijt}}$ is normalized price (generic or originator, defined below), $S_{i j t}$ is generic volume share; $R_{i j t-2}$ is molecule sales in the presentation-country lagged 2 quarters; $\mathrm{D}_{\mathrm{ijt}-2}$ is a vector of (lagged) originator defense strategies; $\mathrm{F}_{\mathrm{ij}}$ is a vector of indicators for non-oral forms; and $\mathrm{M}_{\mathrm{ij}}$ is molecule-specific characteristics. $\mathrm{Z}_{\mathrm{t}}$ is a vector of indicators for two time periods, 2002-05 and 2006-09, that test for changes in the dependent variable, relative to the referent period, 1998-2001.

We estimate separate regressions for each country, to permit all coefficients to vary by country. Other details of the estimation approach are reported in Section VI.B., with reporting of regression results. We now discuss the rationale for included variables and their measurement:

\section{Any Generic (G) and Number of Generics (N)}

Sales $(R)$ : We postulate the same model for entry of Any Generic and Number of Generics, conditional on entry, but allow parameter estimates to differ. Following Bresnahan and Reiss (1991), Scott Morton (1999, 2000) and others, equations (1) and (2) hypothesize that any generic entry and number of generic competitors in a presentation-market depend on the market size ( $R$, gross sales), assuming certain fixed entry cost per firm, due to regulatory and other entry requirements that may differ across countries. Market size is measured by annual sales at manufacturer prices in the retail and hospital channels combined, lagged two quarters. ${ }^{12}$ Costs of entry differ by formulation (F), with higher manufacturing and regulatory costs for intravenous, topical, and other complex forms compared to simple oral solids (tablets and capsules).

\footnotetext{
${ }^{12}$ The appropriate lag for the Originator sales variable depends on when generic firms make entry decisions. If potential entrants accurately project market sales at the time they are likely to enter, our two quarter lagged revenue measure should reasonably characterize the expected relative market size that was relevant to generic decisions to undertake entry.
} 
Originator Defense Strategies (D): We test for effects of three potential originator defense strategies: Number of Licensees, Number of New Originator Formulations launched just prior to patent expiry, and OTC share, all lagged two quarters. Originators may have incentives to launch co-branded licensees to steel share and pre-empt generic competitors in physiciandriven generic markets with brand competition. Such incentives are not expected in pricecompetitive, pharmacy-driven markets such as the U.S., except for authorized generics launched during the Paragraph IV exclusivity period. ${ }^{13}$ Incentives to launch improved formulations, such as extended release forms, may exist in both pharmacy and physician-driven markets, because generic substitution is only permitted within a formulation. The originator's incentive to launch new formulations close to patent expiry of older forms is increased if the new forms receive some additional patent or regulatory exclusivity and can be reimbursed at prices above the price of generic versions of the older formulations. Such conditions exist in the U.S., where aggressive marketing can successfully switch physicians/patients to the new, protected forms and away from the patent-expiring form which faces generic entry. However, launching new formulations is less likely to be profitable in countries where reference pricing or similar reimbursement rules limit reimbursement for all formulations of a molecule to the lowest price per daily dose for that molecule, which is likely to be a generic once the patent expires on any formulation in the molecule. Finally, for molecules that meet regulatory requirements for patient self-medication, originators may launch an over-the-counter (OTC) formulation to preempt generic competition in the Rx formulation after patent expiry.

Molecule Global Age, Launch Lag and Diffusion (M) and Form (F): Molecule Global Age (months since first launch of the molecule in any of our sample countries, hereafter "global launch”) is included as a proxy for unobserved patent term. The greater Molecule Global Age, the more likely that unobserved patents and other exclusivity barriers to entry have expired. Country-specific Molecule Launch Lag (months from global launch to first launch in country j) is a proxy for country-specific data exclusivities that usually run from the originator's countryspecific launch. It is also expected to be positively associated with generic entry. Global

\footnotetext{
${ }^{13}$ In the U.S., several originator firms in the early 1990's launched their own generic products to compete with true generics; however this strategy simply accelerated the downward pressure on generic prices and was abandoned. Originator launch of generics in the U.S. is now confined to "authorized generics" launched during the 180-day exclusivity period awarded to paragraph IV challengers, when prices remain high because only one ANDAapproved generic competitor is present..
} 
Diffusion, measured as the number of countries in our sample in which the molecule is launched, is an indicator for availability of foreign supply sources and possible economies of scale for generic suppliers; it is expected to be positively associated with entry. A vector of Formulation indicators (F) controls for formulations (extended release, intravenous, topical, other complex forms) that have higher manufacturing and/or regulatory costs than the referent oral solid forms, and are therefore expected to attract less generic entry.

Regulatory Changes (Z): Entry incentives depend on regulatory and reimbursement provisions, which differ by country and over time within country. Because regulatory and reimbursement policies affecting generics differ significantly across countries and several countries changed multiple policies over our time period, we use two indicator variables for years 2002-2005 and 2006-2009 to measure the combined effects of country-specific policy changes. The referent period is 1998-2001.

\section{2. $\quad$ Normalized Generic Price}

Our measure of generic price $\mathrm{P}_{\mathrm{ijt}}{ }^{\mathrm{G}}$ for presentation $\mathrm{i}$ in country $\mathrm{j}$ in period $\mathrm{t}$ is the volumeweighted average generic price for all generic versions of presentation ijt, normalized (divided) by the earliest originator price for presentation $\mathrm{i}$ in country $\mathrm{j}$ in our dataset. This normalization yields a unit-free measure of price that permits comparison of trends over time and across molecules and countries, for products with very different absolute price levels. It is independent of exchange rates and country-specific changes in the originator price. ${ }^{14}$

Number of Generic Competitors ( $N$ ): Under standard models of competition, normalized generic price is expected to be inversely related to number of generic competitors, with a greater effect for unbranded generic competitors $\left(\mathrm{N}^{\mathrm{u}}\right)$ than for branded generic competitors $\left(\mathrm{N}^{\mathrm{b}}\right)$. The effect of generic competitors on price is expected to be greater in countries with pharmacydriven vs. physician-driven markets. ${ }^{15}$

Regulatory Changes (Z), Formulation (F), and Molecule Characteristics (M): Time period indicators are included to capture effects of regulatory and reimbursement changes that affected generic prices directly, such as the change in reimbursement rules in the U.K., reference

\footnotetext{
${ }^{14}$ Several previous papers use the contemporaneous generic/brand price ratio, which may confound changes in generic prices in the denominator with changes in originator prices in the numerator.

${ }^{15} \mathrm{~N}$ can be treated as predetermined in the price equation due to the regulatory lag in getting market authorization. In the U.S., this takes at least a couple of years.
} 
pricing in France, or sickness fund contracting in Germany. Formulation indicators and Global Diffusion control for cost differences.

\section{Normalized Originator Price}

We estimate a similar model of normalized originator price $\mathrm{P}_{\mathrm{ijt}}{ }^{\mathrm{O}}$, also normalized to the earliest originator price for the same presentation in the dataset. Frank and Salkever $(1992,1997)$ and Regan (2008) have argued that originators pursue a segmentation strategy that leads to increased originator price in response to generic competition. Although this may have been an optimal strategy in the 1990's in the U.S., this may no longer be true in the 2000's, given the growth of insurance plans that require patients to pay the difference between the generic co-pay and the originator price or third-tier co-payment.. In most countries other than the US, including the U.K., price regulatory systems disallow post-launch originator price increases and, more generally, may make segmentation pricing strategies infeasible and/or non-optimal. In countries with generic reference pricing, such as Germany and France, although pricing above the reference price is permitted in theory, in practice originators usually cut price to the reference price because patient demand is very elastic above the reference price (see Stargardt, 2010, for recent evidence from Germany). Thus normalized originator prices are expected to be flat or declining after generic entry in most countries. It is an empirical question whether increasing price in response to generic entry remains an optimal strategy in the US and possibly Mexico, where price regulation is weakly enforced.

\section{Generic Volume Share}

Generic volume share is expected to be inversely related to generic price in pharmacydriven markets. In physician-driven markets, price sensitivity is expected to be weaker, especially for branded generics and before reforms to stimulate price sensitivity. Simultaneous determination of price and volume is expected in countries where generic prices are competitively determined (U.S., U.K.). We therefore estimate eq. (4) with both OLS and twostage least squares (2SLS), in which generic price is treated as endogenous using the hospital price and an indicator for chronic medications as instruments. For other countries where generic

prices are set by regulation or constrained through RP reimbursement, generic prices may be less responsive to market conditions, in which case OLS estimation may be appropriate. The Generic 
Volume Share equations also include as control variables: number of branded and unbranded competitors (treated as predetermined), generic age (months since first generic launch of presentation i in country j), formulation and molecule effects, as well as time dummies to capture regulatory changes.

\section{Results}

\section{A. Descriptive Analysis}

We first characterize the cross-national differences in generic markets using graphic analysis to compare generic entry, generics prices and shares across countries. For some variables, we compare starting (1998-2001) and ending (2006-2009) values, hereafter referred to as 2001 and 2009. For other variables, we show average values over the entire period to conserve space, but note that this masks the changes over time, which are discussed later. Descriptive statistics are reported in Appendix Table 1.

\section{Any Generic and Number of Generics}

Almost all countries experienced an increase in the percent of molecules in the 8-20 year cohort with generic entry over the 2000's decade (Figure 1). France had the largest percentage increase from 7 to 25 percent. Brazil has the highest generic presence, with 41 percent of molecules age 8-20 years having a generic, plausibly reflecting similares that entered before patent protection.

Figure 2 shows the effective patent life or mean age of the originator at first generic entry for the molecule (Generic launch lag). ${ }^{16}$ The low initial values in 2001 for Spain (8.1 years) and Italy (8.7 years) may reflect originator-initiated ("authorized") generics that do not represent a true generic challenge to effective patent life. Over time, generic launch lags decline in some countries, including France, Germany and the U.K., reflecting more rapid entry possibly in response to pro-generic policies. Generic launch lags increased in Italy, Spain, Brazil and Mexico, possibly reflecting fewer copy products as enforcement of IP improved. In the U.S. the mean generic lag increased minimally, from 11.2 in 2001 to 11.4 in 2009. This suggests that any

\footnotetext{
${ }^{16}$ A small number of generic launches reportedly occurred within 5 years of the originator launch. We treated such early launch dates as implausible and excluded them from these calculations in all countries except Brazil, Chile, Mexico, Italy, and Spain, which had late or weak patent enforcement.
} 
increase in Paragraph IV patent challenges was on average offset by increased use of exclusivity extensions, such as for pediatric trials. Effective patent life is almost two years longer in the US (11.3 years) than in Canada (9.4 years).

Once generic entry occurs, in most countries the number of generic manufacturers increases initially and reaches a plateau roughly two years from first generic entry (Figure 3). Germany has the most generic manufacturers per presentation, averaging 9 by quarter 5 , followed by France and Japan at 5-6, all traditionally branded generic markets. By contrast, the U.S. averages 4-5 generic manufacturers per presentation. Although Brazil and Mexico have a high proportion of molecules with generic presence, they have relatively few (1-2) generics per presentation.

This evidence of more generics per presentation in countries other than the U.S. is prima facie surprising because the U.S. has much larger sales, by value or volume, than other countries (Table 2-3). Country-specific studies (e.g. Scott Morton, 1999) have consistently found a strong relationship between number of generic entrants and sales, consistent with standard entry models with fixed costs (Bresnahan and Reiss, 1991). This cross-national evidence of more manufacturers per presentation in much smaller markets than the US implies that the gross sales value necessary to attract generic entry is lower in other countries, plausibly due to higher expected generic prices and less price-competitive generic markets in other countries.

To provide evidence on this, Table 3 shows median annual sales per generic manufacturer and price per dose at 2 years since generic entry, overall and by number of generics per presentation. All other countries (except Japan) have lower overall average gross sales per generic manufacturer and higher average price per dose than the U.S., followed by the U.K. ${ }^{17}$ Price per dose is relatively high (\$0.88) in the U.S. for presentations with only one generic, which would primarily reflect paragraph IV exclusive markets. However, for the typical presentation with at least 4 generics, the U.S. average price $(\$ 0.23)$ is lower than all other countries except the U.K. (\$0.22). Conversely, Canada has the highest generic prices and lowest sales per manufacturer, plausibly due to regulatory barriers to price competition. The decline in average generic price with number of manufacturers is greater in the U.S. and the U.K. than in other countries - indeed, the relationship is positive or flat in Canada, Italy, Japan and Mexico.

\footnotetext{
${ }^{17}$ Japanese price are lower on a per dose basis because average grams of active ingredient per dose are consistently lower in Japan than in most other countries (Danzon and Furukawa, 2008).
} 
This evidence is consistent with the branded and/or price-regulated generic markets being less price competitive than the U.S. and U.K., enabling generics firms to survive on lower gross sales per presentation than is feasible in the more price competitive U.S. or U.K. markets. ${ }^{18}$

Figure 4 shows the life-cycle of normalized generic prices by quarter since first generic entry. ${ }^{19}$ In the U.S., generic prices are initially 75 percent of baseline originator price, consistent with limited competition during the paragraph IV exclusivity period. Thereafter, generic prices drop rapidly to 36 percent of baseline originator price after two years. The U.K., Germany and Mexico also have declining generic prices after generic entry but at higher levels - declining after two years to 60 percent of the originator price in the U.K., 50 percent in Germany and 72 percent in Mexico. In all other countries, generic prices are relatively flat over time, at 50-70 percent of baseline originator prices, despite entry of more competitors shown in Figure 3. This evidence of relatively high normalized price levels that are flat over time despite competitive entry is consistent with the hypothesis of weak price competition in physician-driven, branded generic markets, despite multiple generic competitors per presentation.

Figure 5 shows that normalized originator prices are generally stable in response to generic entry, but at different levels reflecting different regulatory regimes. In the U.S., the mean normalized originator price is 1.24 at generic entry, reflecting the increase in real originator prices over time prior to patent expiration that is common in the U.S. ${ }^{20}$ However, whereas some earlier studies found that originator prices increase in response to generic entry (Frank and Salkever, 1997; Regan, 2008), our results show a modest decline in originator prices after generic entry in the U.S. from 1.24 to 1.13, possibly reflecting the smaller size of the brand loyal market in recent years compared to the time of these earlier studies. In Germany and France, originator prices decline by 21 and 12 percent, respectively, in the 2 years post generic entry, plausibly reflecting the incentive of originators to cut prices to the reference price in these countries. In most other countries originator prices are stable over the two years following

\footnotetext{
${ }^{18}$ These IMS prices may be upward biased for true transactions prices in countries where off-invoice discounts to pharmacies are common. These discounts average over 30 percent in the U.S. (CBO, 2005). The fact that gross sales per generic are smaller in other countries than in the U.S. makes it unlikely that any unobserved discounts are greater in other countries than the U.S.

${ }^{19}$ Recall that normalization is to the earliest originator price available in our dataset ("baseline originator price"), which is invariant over time for each presentation. Although these baseline originator prices are observed at different originator ages, including some that occur after generic entry, given the stability of originator prices (see Figure 5) this should not matter. Moreover the normalization is invariant over time for a given presentation, so measures of generic price change over time are unaffected by differences across molecules in the baseline originator age.

${ }^{20}$ Recall that we deflate all nominal prices by the country-specific general Producer Price Index.
} 
generic entry, between 70-90 percent of baseline prices (except 60 percent for Italy), consistent with regulatory constraints on price increases and possibly some mandatory cuts. .

Conditional on generic entry, generic penetration is most rapid and reaches the highest peak in the U.S. (89 percent of unit volume in two years), followed by Canada (74 percent) (Figure 6). High generic penetration in Canada, despite its high regulated generic prices, is consistent with the hypothesis of extensive off-invoice discounting to pharmacies that is not captured by payers or in the IMS data. Ontario has recently taken steps to change this system. ${ }^{21}$ The U.K. also has relatively rapid generic adoption due to strong pharmacy substitution incentives. In Germany the rapid generic adoption presumably reflect both drug budgets for physicians and requirements for generic substitution adopted during the 2000s. Japan and Italy have the lowest generic shares (under 40 percent).

Over the 2000's, most countries experienced growth in generic uptake, primarily due to growth in unbranded generics (Figure 7). Of the four E.U. countries that adopted significant progeneric policy changes (France, Germany, Italy and Spain) all started with relatively high branded generic shares in 2000 but achieved growth in unbranded and total generic penetration over time, except Italy, where growth in unbranded share is more than offset by decline in branded generic share. Although at the start of the period only the U.S., Canada and the U.K. had predominantly unbranded generics, by the end this was also true for France, Germany, and Spain. By contrast, Brazil and Mexico remain predominantly branded, and Japan is roughly evenly split, but with a very low generic share.

\section{B. Multivariate Regressions}

Appendix Tables 2-5 report the full regression analysis of determinants of generic entry, generic and originator prices and generic market shares, for branded and unbranded generics combined, to conserve space. Summary Tables 4-7 report key coefficients, including coefficients with branded and unbranded generics measured separately. We estimate separate equations for each country, to permit all coefficients to vary across countries. The unit of observation is the country-quarter-presentation (molecule-formulation-strength). We report marginal effects with robust standard errors and clustering by molecule to address unobserved molecule-specific effects. Some explanatory variables that are treated as pre-determined are lagged two quarters.

\footnotetext{
${ }^{21}$ See http://www.mercer.ca/referencecontent.htm?idContent=1377645\&siteLanguage=1007, accessed 6/24/2011.
} 
We report probit estimates for the Any Generic equation and use a negative binomial estimator for the Number of Generics equation. Results are robust to alternative estimation methods, including OLS and zero-inflated negative binomial models. ${ }^{22}$ To address the potential endogeneity of price in the volume share equations for countries where generic prices are determined by market competition (especially the U.S. and U.K.), we estimated both OLS and two-stage least squares (2SLS) via generalized method of moments (GMM). Instrumental variables are generic price in the hospital channel and an indicator for therapeutic classes that treat chronic conditions. These results are reported below the OLS estimates in Table 4.

\section{Any Generic and Number of Generics}

The probability of Any Generic and Number of Generic manufacturers conditional on entry are both positively related to lagged log sales in almost all countries (Table 4), consistent with standard theories of entry in markets with fixed costs and evidence from previous studies. The exception is that Any Generic is not significantly related to sales in the U.S., suggesting that even small markets attract generic entry. In the traditionally physician-driven, branded generic markets of France, Germany, Spain and Italy, the responsiveness of entry to sales is higher for unbranded generics than for branded generics, as expected if unbranded generics are typically lower priced and therefore need larger sales volume to break even.

The evidence in Appendix Tables 2-3 suggests that proliferation of licensee brands by the originator does deter entry of any generic in Italy, consistent with Magazzini et al. (2004), but not in other countries. ${ }^{23}$ There is no support for the hypothesis that licensees reduce the Number of Generics, conditional on entry, in any country. Thus, this more recent evidence conflicts with earlier findings for Canada (Hollis, 2003) and Germany (Appelt, 2009), possibly because a brand saturation strategy becomes ineffective as a generic entry deterrent as generic markets become more unbranded and pharmacy-driven, as competition shifts to price rather than brand. ${ }^{24}$

\footnotetext{
${ }^{22}$ We do not estimate a hazard model for generic launch because defining the starting point is conceptually and empirically problematic, given that patents can be challenged, and we lack data on expected expiry dates for patents and data exclusivities.

${ }^{23}$ The marginally significant negative coefficient on licensees in the Any Generic equation for the U.S. is probably spurious. Licensee proliferation is irrational in a market dominated by pharmacy substitution, and co-branding is extremely rare in the US. The mean number of licensees in the U.S. (0.42) compared to Italy (0.76) and Germany (0.86) is consistent with the hypothesis that licensing co-branded pseudo-competitors is a less common strategy for originators in the U.S. than in physician-driven, branded generic markets.

${ }^{24}$ The significantly positive licensee coefficients for Number of Generics in Spain and Brazil may reflect coding error, because licensees in these countries may be local branded generics manufacturers.
} 
The originator defense strategy of launching alternative formulations shortly prior to patent expiry does deter any generic entry in the U.S. and also reduces number of generic entrants in the U.S. and Canada, but not in other countries. This evidence that launching new formulations is uniquely effective in the U.S. (and partially effective in Canada) is consistent with the hypothesis that U.S. reimbursement systems facilitate both switching patients and maintaining high prices for these new forms, compared to price-regulated markets which often reimburse new formulations at the same price as older versions of the same molecule under reference pricing.

Extended release, intravenous, topical and other complex formulations are much less likely to attract generic entry than oral solids in multiple countries, plausibly due to higher manufacturing and possibly regulatory costs. OTC market share of the presentation does not deter Any Generic entry but does reduce number of generic entrants in the U.S., plausibly because OTC prices are relatively cheap in the U.S. and hence offer consumers a popular alternative to generic Rx versions, although the OTC forms are not covered by insurance. OTC effects are also negative for France. Hospital share of sales is negatively related to Any Generic and Number of Generics in most countries. ${ }^{25}$ This suggests that hospitals markets are less attractive to generics than retail pharmacy sales, possibly because originators give large price discounts to hospitals in most countries, including in countries that regulate retail prices. ${ }^{26}$ Molecule Global Age is positively related to Any Generic and Number of Generics, confirming that this variable is a rough proxy for unobserved patent terms. Delay in originator launch is negatively related to Any Generic and Number of Generics in the U.S., with less consistent effects in other countries, suggesting that data exclusivities that run from countryspecific molecule launch are a more binding barrier to generic entry in the U.S. Global Diffusion of a molecule is positively associated with Number of Generics in Canada, Germany, Spain, Brazil and Mexico, suggesting that availability of foreign supplies of active ingredients and/or finished product facilitates generic entry in these countries, because local generic firms rely on foreign suppliers.

\footnotetext{
${ }^{25}$ The IMS data do not report hospital sales for the Latin American countries.

${ }^{26}$ Scott-Morton (1999) found a positive relation between hospital share and generic entry. Magazzini et al. (2004) found a negative relation between hospital share and unbranded generic share in a regression that pooled 4 countries, including the U.S.
} 


\section{2. $\underline{\text { Prices }}$}

Normalized Generic Prices: Previous studies of U.S. generic markets have consistently shown that generic prices decline with number of generic competitors. Whether price competition works as effectively for physician-driven, branded generics markets and how this has changed over time are important empirical questions addressed in Appendix Table 4, summarized in Table 5.

Normalized generic prices are negatively related to number of unbranded generics in most countries, and unbranded generics are more effective at reducing prices than branded generics in Germany, Italy, Spain, Brazil and Mexico, as predicted. Prices are unrelated to number of competitors in France, suggesting that the reference price system and other regulations may have blunted price competition. In Japan, generic prices are negatively related only to branded generics, possibly because unbranded generics are still uncommon. Unbranded and branded generics have similar and large negative effects on price (0.076 and 0.097 percent, respectively) in the U.K., where aggressive pharmacy substitution plausibly forces both branded and unbranded generics to compete on price. In Canada an additional branded or unbranded generic reduces generic price by only 0.01 percent, plausibly due to regulation of generic prices that applies to both unbranded and branded generics. In Mexico generic prices are positively related to number of branded suppliers.

Normalized Originator Prices: Consistent with our graphical analysis, multivariate regression analysis shows no evidence that originator prices increase with number of generics in the U.S. (Table 5), contrary to segmentation theory and previous evidence (Frank and Salkever, 1997; Regan 2008). The measured effect for number of unbranded generics is negative but very small (0.006) and only marginally significant in the U.S. By contrast, originator prices are negatively related to the number of unbranded generics but number of branded generics has no effect in France, Italy and Spain. This suggests that the reference pricing systems in these countries have brought down originator prices and, together with other measures, have encouraged the entry of unbranded generics that compete on price.

\section{Generic Volume Shares}

Table 6 reports effects of generic prices on generic volume shares for OLS and 2SLSGMM estimators. Endogeneity of generic prices is plausible in the U.S. and the U.K., where generic prices are unregulated and generics compete on price to gain market share. The 2SLS 
estimates pass tests for instrument validity and overidentification in all countries. For other countries where generic prices are either regulated or constrained by reference pricing, and competition focused on brand rather than price at least initially, prices are less endogenous to share, and OLS results may be plausible. For most countries the OLS and 2SLS results are similar, with 2SLS showing slightly more negative share elasticities than OLS, especially in Canada. ${ }^{27}$

Generic volume shares are significantly negatively related to generic prices in the U.S., the U.K. and Canada, the three countries with pharmacy-driven generic markets throughout the period, and also in France and Germany, which adopted measures to stimulate switching to cheaper generics over the 2000's. The estimated elasticity of volume with respect to price for Canada is much more negative using 2SLS (-1.114) than OLS (-0.382), which suggests that the hospital generic price we use as an instrument is a more accurate indicator of the true exmanufacturer price to pharmacists, net of unobserved discounts, than the official retail price reported in the IMS retail data.

Generic price has no significant effect on generic share in Italy, Spain and Japan. The lack of price sensitivity is unsurprising in Japan, because physicians' absolute dispensing margins tend to increase with drug price. Lack of price sensitivity in Italy and Spain may reflect reference price reimbursement systems that encourage originators to drop their price to the reference price (Garratini and Ghislandi, 2006), thereby eliminating financial incentive for physicians/patients/pharmacists to prefer generics. The estimated OLS effect of generic price on share is positive in Mexico, despite its predominantly self-pay market. This is consistent with the hypothesis that consumers purchase on brand rather than price when quality is uncertain due to lack bioequivalence requirements (Danzon, Mulcahy and Towse, 2011).

Generic shares are also positively related to Generic Age (years since generic entry), consistent with standard diffusion models. Controlling for price, generic shares are positively related to number of generic manufacturers in most countries; however, we treat this primarily as a control variable due to the possibility of endogeneity.

\footnotetext{
${ }^{27}$ For Brazil and Mexico, 2SLS cannot be estimated due to lack of data on hospital price which is used as an instrument.
} 


\section{Effects of Policy Changes}

To provide a rough measure of the effects on generic entry, prices and shares due to policy changes and other factors over our time period, the regressions include two indicator variables, for years 2002-2005 and years 2006-2009, with the initial period 1998-2001 as the referent. Table 7 reports the coefficients on the 2006-2009 indicators, with tests for significance of change relative to the initial period.

The probability of Any Generic has increased significantly in the U.S., ${ }^{28}$ the U.K., France and Germany, all of which have adopted measures to promote generic entry. Number of generic manufacturers per presentation, conditional on entry, has increased significantly in France, Germany, Italy and Brazil, with positive but less significant effects in Spain and Mexico. Interestingly, the number of branded generic manufacturers has declined significantly in the U.K., Germany, Italy, Spain and Japan, while the number of unbranded generic manufacturers has increased significantly in all countries except the U.S., U.K. and Canada, which had strong unbranded generic presence and pharmacy-driven markets initially, and Mexico. Thus, the policy changes have clearly had some success in promoting entry of unbranded generics.

Normalized generic prices have declined in all countries except in the U.S., which already had very low generic prices. The large decline in U.K. generic prices plausibly reflects the changes in generic reimbursement adopted in 2005. Normalized originator prices declined in all countries except the U.S. and Mexico, where they increased, and Canada with no change.

Generic share of volume, conditional on generic presence, has increased significantly in the U.S., U.K., France, (Japan) and Brazil. With the exception of Brazil, this generic share growth is due almost entirely to unbranded generics, which have also had very modest share growth in Japan. Thus, the policy changes in the E.U. countries appear to have increased the number of generics and their market share, with greatest growth (18.8 percent) in France. The U.S. and the U.K. have also seen 18.2 and 15.5 percent, respectively, increase in generic market shares. The largest decline in generic prices was in the U.K. (33 percent), followed by France, Italy, Spain and Brazil (25-29 percent).

\footnotetext{
${ }^{28}$ The U.S. 2003 MMA limited originator incentives to use patent proliferation to deter generic entry, by permitting only one 30 month stay per product.
} 


\section{Savings from Generics}

Payer savings from generics depends on the generic-originator price difference and on the share of prescriptions that are dispensed generically. ${ }^{29}$ We calculate the percent savings from generic price, generic unit volume and generic savings as a percent of total drug spending in 1998-2001 and 2006-2009, calculated as follows (where Q denotes units, P denotes price, superscripts $\mathrm{O}$ and $\mathrm{G}$ denote originator and generic, respectively): Percent savings in price, [( $\mathrm{P}^{\mathrm{O}}$ $\left.\left.\mathrm{P}^{\mathrm{G}}\right)^{*} \mathrm{Q}^{\mathrm{G}}\right] /\left(\mathrm{P}^{\mathrm{G}^{*}} \mathrm{Q}^{\mathrm{G}}\right)$, measures the counterfactual percent increase in cost if all genericallydispensed units were sold as originators; Percent savings in volume, $\left(P^{G} * Q^{G}\right) /\left(P^{G} * Q^{G}+\right.$ $\mathrm{P}^{\mathrm{O} *} \mathrm{Q}^{\mathrm{O}}$ ), is the generic share of unit volume for molecules in our 8-20 year cohort, weighted by their respective prices; Total percent savings for the 8-20 age cohort, $\left[\left(\mathrm{P}^{\mathrm{O}}-\mathrm{P}^{\mathrm{G}}\right)^{*} \mathrm{Q}^{\mathrm{G}}\right] /\left(\mathrm{P}^{\mathrm{O} *} \mathrm{Q}^{\mathrm{G}}+\right.$ $\mathrm{P}^{\mathrm{O} *} \mathrm{Q}^{\mathrm{O}}$ ), measures how much higher expenditure would be if there were no generics for drugs in the 8-20 year cohort. An alternative Total savings measure calculates the generic savings for the 8-20 year cohort as a percent of total expenditure on all drugs. The estimates for each time period and country are in Table 8, which also reports the change in savings between the early and later periods.

Savings from low generic prices are far greater in the U.S. than in any other country in 2001, but by 2009 the U.K. prices yield similar savings and the U.K. therefore has the greatest increase in price savings over the period. Of course, these estimates are sensitive to the originator prices, which are relatively high in the U.S., but the U.S. generic prices are also absolutely low relative to other countries (Table 3).

The savings from generic share of unit volume increased most in France, from 7 percent in 2001 to 55 percent in 2009. As of 2009, generic shares of the 8-20 year cohort total volume are higher in Canada, the U.K., France and Germany than in the U.S., because although the U.S. has the highest generic penetration conditional on generic entry, Canada, France and Germany on average have earlier generic entry, presumably due to fewer patent extensions for originators. Thus although Paragraph IV challenges have shortened expected patent life for some drugs,

\footnotetext{
${ }^{29}$ Our savings calculations ignore any change in total (originator plus generics) unit volume of the molecule following generic entry. In theory lower generic prices might induce increased utilization of molecules with generics, including therapeutic substitution away from similar, on-patent molecules. In practice, U.S. evidence generally indicates no increase in utilization at the molecule level following generic entry, plausibly because any positive response to lower prices is offset by the decline in originator promotion that occurs in markets with pharmacy substitution, unless payers aggressively encourage therapeutic substitution, as some payers did when generic simvastatin became available in the statin class.
} 
originators in the U.S. on average lose less volume share to generics than originators in these other countries in the 8-20 year phase of originator life. Relatively high originator prices in the denominator also reduce our measure of volume savings for the U.S.

The total generic savings on the 8-20 year cohort are highest in the U.K. and the U.S., which would have spent 272 percent and 238 percent more, respectively, on these drugs, in the absence of generics. Canada, France and Germany would have spent 43-55 percent more, in the absence of generics. Among the E.U. countries which made major changes, only France has significant increase in savings (39.3 percentage points) from 1998-2009. In Germany savings on price and total savings appear to have declined, even though volume share increased; however, price savings in Germany may be understated if the discounts granted directly to sickness funds are not reflect in IMS price data. Spain has modest declines in price and volume savings from generics, possibly because reference pricing has reduced prices but increased volume share for originators. And such savings, due to the effect of generics on originator prices, are not reflected in our estimates of savings due to generics.

Generic savings as a share of total drug spending is under 10 percent in all countries except the U.S. and U.K. However, this measure is heavily influenced by on-patent originator prices in the denominator, which reflect policies to encourage $R \& D$ and other factors. This Total savings measure is therefore less relevant as a measure of savings achieved by policies to encourage generics than the measures which report savings relative to total sales for the 8-20 year cohort.

\section{Conclusions}

Cross-national differences in policies towards generics have resulted in major differences in generic entry, generic prices and generic market shares, and in whether generic markets are pharmacy-driven with unbranded generics, as in the U.S. and U.K., or physician driven with branded generics, as has traditionally been the norm in most other countries. Over the last decade, policies adopted in France, Spain, Italy and Germany to increase generic uptake and price-competitiveness have resulted in some growth in the share of unbranded generics in these countries. Reference pricing policies may have stunted the growth of generic shares and price competition, although to the extent that they also reduce originator prices, they yield savings without generic adoption. As of 2009, the policy changes appear to have been most effective in 
France, which experienced a large increase in generic penetration and some reduction in generic prices, whereas incremental savings were at most modest in Italy, Spain and Germany. The U.K.'s policies to reduce generic reimbursement prices have also achieved very significant price savings and increased generic penetration. Although the data do not permit precise measurement of individual policy effects, these results are consistent with the hypothesis that policies to shift generic markets from physician-driven, branded generics towards pharmacy driven, unbranded generics, can potentially yield significant savings to payers, provided that these policies are appropriately designed such that payers rather than pharmacies capture most of the savings.

\section{References}

Appelt, S. 2009. Early entry and trademark protection - an empirical examination of barriers to generic entry. Paper presented at the Summer Conference 2009, Copenhagen Business School.

Berndt, E.R., Aitken, M.L. 2010. Brand loyalty, generic entry and price competition in pharmaceuticals in the quarter century after the 1984 Waxman-Hatch Legislation. NBER Working Paper No. 16431.

Bresnahan, T.F., Reiss, P.C., 1991. Entry and competition in concentrated markets. Journal of Political Economy 99, 977-1009.

Danzon, P.M., Furukawa, M.F., 2008. International prices and availability of pharmaceuticals in 2005. Health Affairs 27, 221-233.

Danzon, P.M., Mulcahy, A.and Towse, A.2011. Pharmaceutical pricing in emerging markets: effects of income, competition and procurement. NBER Working Paper.

Ellison, G., Ellison, S.F., 2011. Strategic entry deterrence and the behavior of pharmaceutical incumbents prior to patent expiration. American Economic Journal: Microeconomics 3, 1-36.

Frank, R.G., Salkever, D.S., 1992. Pricing, patent loss and the market for pharmaceuticals. Southern Economic Journal 59, 165-179.

Frank, R.G., Salkever, D.S., 1997. Generic entry and the pricing of pharmaceuticals. Journal of Economics \& Management Strategy 6, 75-90.

Garattini, L., Ghislandi, S., 2006. Off-patent drugs in Italy: a short-sighted view? European Journal of Health Economics 7, 79-83.

Ghislandi S, Krulichova I, Garattini L. Pharmaceutical policy in Italy: Towards a structural change? Health Policy 2005; 72: 53-63.

Grabowski, H., Kyle, M., 2007. Generic competition and market exclusivity periods in pharmaceuticals. Managerial and Decision Economics 28, 491502.

Grabowski, H., Vernon, J.M., 1992. Brand loyalty, entry, and price competition in pharmaceuticals after the 1984 Drug Act. Journal of Law \& Economics 35, 331-350.

Grabowski, H., Vernon, J., 1996. Longer Patents for increased generic 
competition in the U.S.: The Waxman-Hatch Act after one decade. Pharmacoeconomics $10,110-123$.

Hollis, A., 2003. The anti-competitive effects of brand-controlled "pseudogenerics" in the Canadian pharmaceutical market. Canadian Public Policy/Analyse de Politiques 29, 21-32.

Hudson, J., 2000. Generic take-up in the pharmaceutical market following patent expiry: a multi-country study. International Review of Law and Economics 20, 205-221.

Kanavos, P., Costa-Font, J., Seeley, E., 2008. Competition in off-patent drug markets: issues, regulation and evidence. Economic Policy 23, 499-544.

Magazzini, L., Pammoli, F., Riccaboni, M., 2004. Dynamic competition in pharmaceuticals: patent expiry, generic penetration and industry structure. European Journal of Health Economics 5, 175-182.

Moreno-Torres, I., Puig-Junoy, J., Borrell, J.R., 2009. Generic entry into the regulated Spanish pharmaceutical market. Review of Industrial Organization 34, 373388.

Pammoli, F., Magazzini, L., Orsenigo, L., 2002. The intensity of competition after patent expiry in pharmaceuticals: a cross-country analysis. Revue D'Economie Industrielle 99, 107-131.

Puig-Junoy, J. 2010. The impact of European pharmaceutical price regulation on price competition: a review. Pharmacoeconomics 28: 649-663.

Regan, T. 2008. Generic entry, price competition, and market segmentation in the prescription drug market. International Journal of Industrial Organization (4):930-948.

Reiffen, D., Ward, M.E., 2005. Generic drug industry dynamics. Review of Economics and Statistics 87, 37-49.

Saha, A., Grabowski, H., Birnbaum, H., Greenberg, P., Bizan, O., 2006. Generic competition in the U.S. pharmaceutical industry. International Journal of the Economics of Business 13, 15-38.

Scott Morton, F., 1999. Entry decisions in the generic pharmaceutical industry. RAND Journal of Economics 30, 421-440.

Scott Morton, F., 2000. Barriers to entry, brand advertising, and generic entry in the U.S. pharmaceutical industry. International Journal of Industrial Organization 18, 1085-1104.

Stargardt, T. 2010. The impact of reference pricing on switching behaviour and healthcare utilization: the case of statins in Germany. European Journal of Health Economics 11:267-277.

U.S. Congressional Budget Office, 2005. Prices for brand-name drugs under selected federal programs. Washington D.C.: Congressional Budget Office. 
Table 1: Regulatory and Reimbursement Rules, by Country

\begin{tabular}{|c|c|c|c|c|c|c|c|}
\hline & $\begin{array}{l}\text { Pharmacy } \\
\text { Generic } \\
\text { Subst. }\end{array}$ & $\begin{array}{c}\text { Pharmacy } \\
\text { reimb based } \\
\text { on price } \\
\end{array}$ & $\begin{array}{l}\text { Discounts to } \\
\text { pharmacies }\end{array}$ & $\begin{array}{c}\text { Generic } \\
\text { RP }\end{array}$ & $\begin{array}{c}\text { Regulated } \\
\text { Generic } \\
\text { Price }\end{array}$ & $\begin{array}{c}\text { Patient co- } \\
\text { pay } \\
\text { incentive, } \\
\text { other than } \\
\text { RP } \\
\end{array}$ & $\begin{array}{l}\text { Physician } \\
\text { Incentive }\end{array}$ \\
\hline US & Yes & No & Yes & Yes & No & Yes & No \\
\hline UK & Yes $^{1}$ & No & Yes & Yes & No & No & Yes \\
\hline Canada & Yes & No & Yes & Yes & Yes & No & No \\
\hline France & 1999 & Pre 2002 & Yes & 2003 & Yes & No & $2000^{2}$ \\
\hline Germany & 2002 & Pre 2007 & $\begin{array}{c}\text { Banned in } \\
2006\end{array}$ & 1989 & No & No & Yes \\
\hline Italy & 2001 & Yes & No & 2001 & Yes & No & No \\
\hline Spain & Yes & No & Yes & 2000 & No & No & No \\
\hline Japan & No & Yes & Yes & No & Yes & Yes & No \\
\hline Australia & 1994 & Yes & Yes & Yes & Yes & No & No \\
\hline Mexico & $\mathrm{No}^{3}$ & No & No & No & No & Yes & No \\
\hline Chile & No & No & No & No & No & Yes & No \\
\hline Brazil & Yes & No & No & No & 2004 & Yes & No \\
\hline
\end{tabular}

${ }^{1}$ INN Rx only for outpatient Rx; also substitution for originator Rx in hospitals.

${ }^{2}$ From 2000, French physicians were required to prescribe at least a specified percent generic, which has increased over time.

${ }^{3}$ Substitution permitted only with interchangeable generics, which were a small share of total volume until 2005 , and if the prescription is generically written. Since over $60 \%$ of Rx-bound medicines are dispensed without an $\mathrm{Rx}$, substitution restrictions may be moot. 


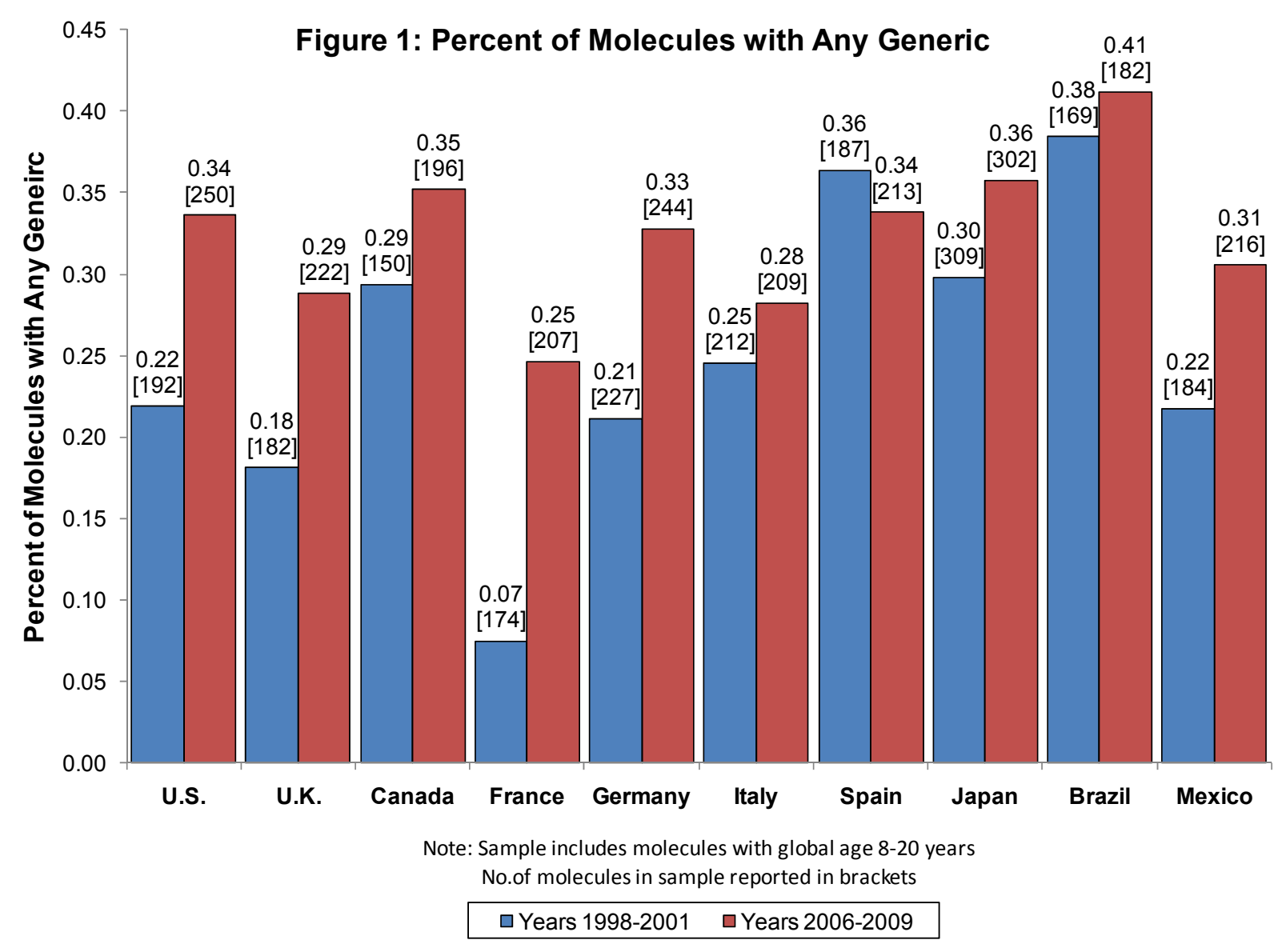

Figure 2: Mean Molecule Age at Generic Entry (Generic Launch Lag)

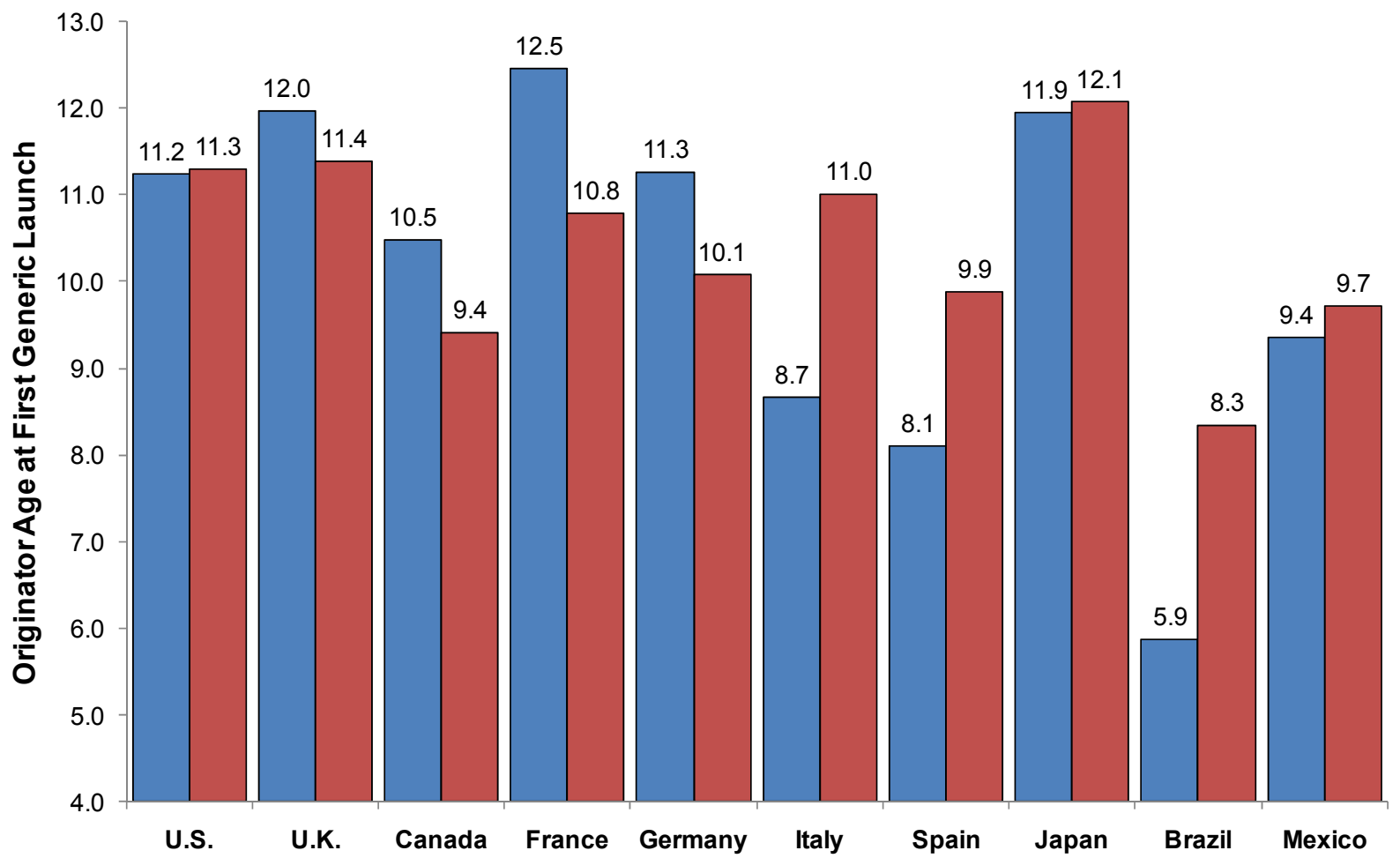

Note: Sample includes molecules with global age 8-20 years

$\square$ Years 1998-2001 $\quad$ पYears 2006-2009 
Figure 3: Generic Manufacturers, By Time Since First Generic Entry

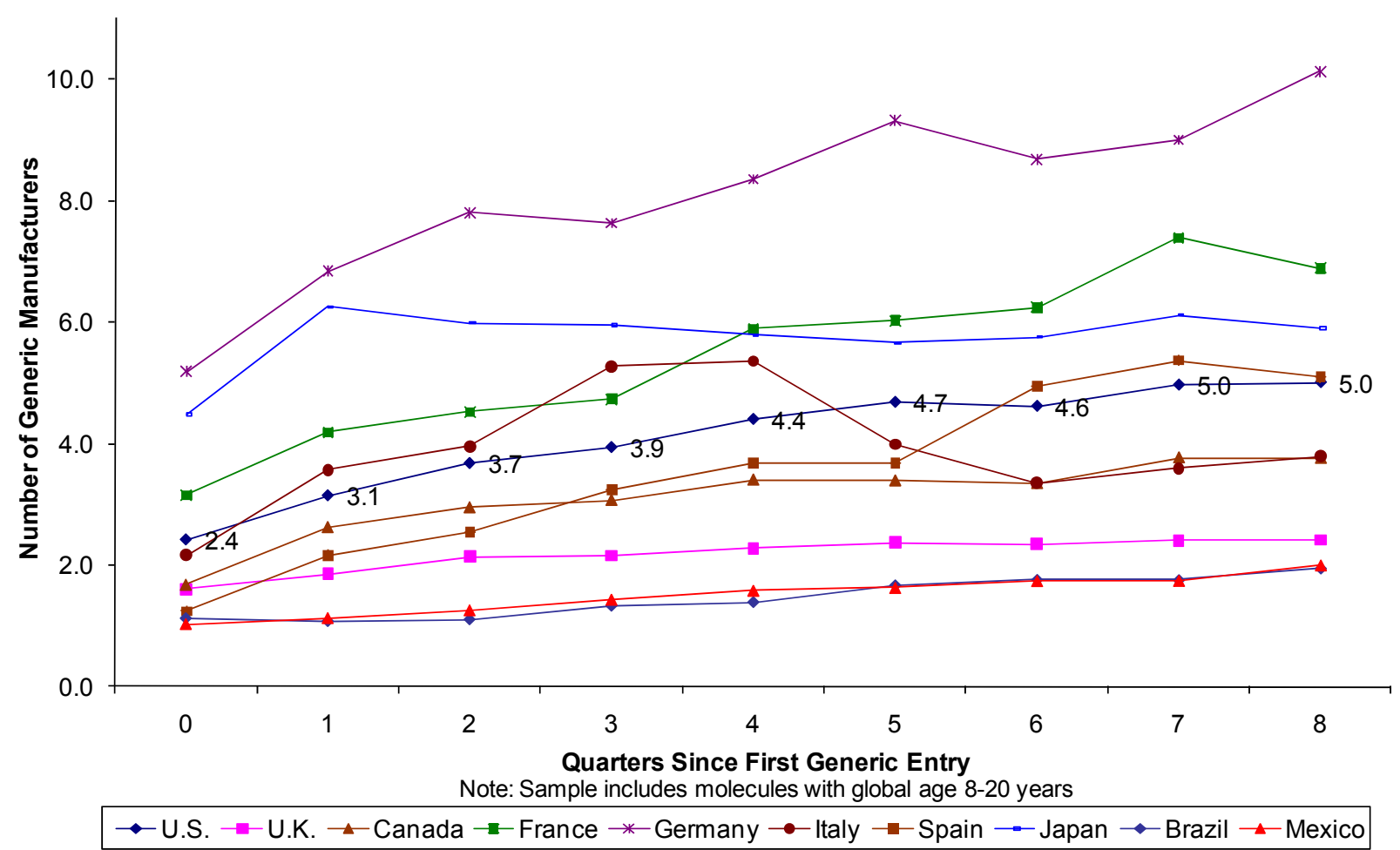

Figure 4: Normalized Generic Price, By Time Since First Generic Entry

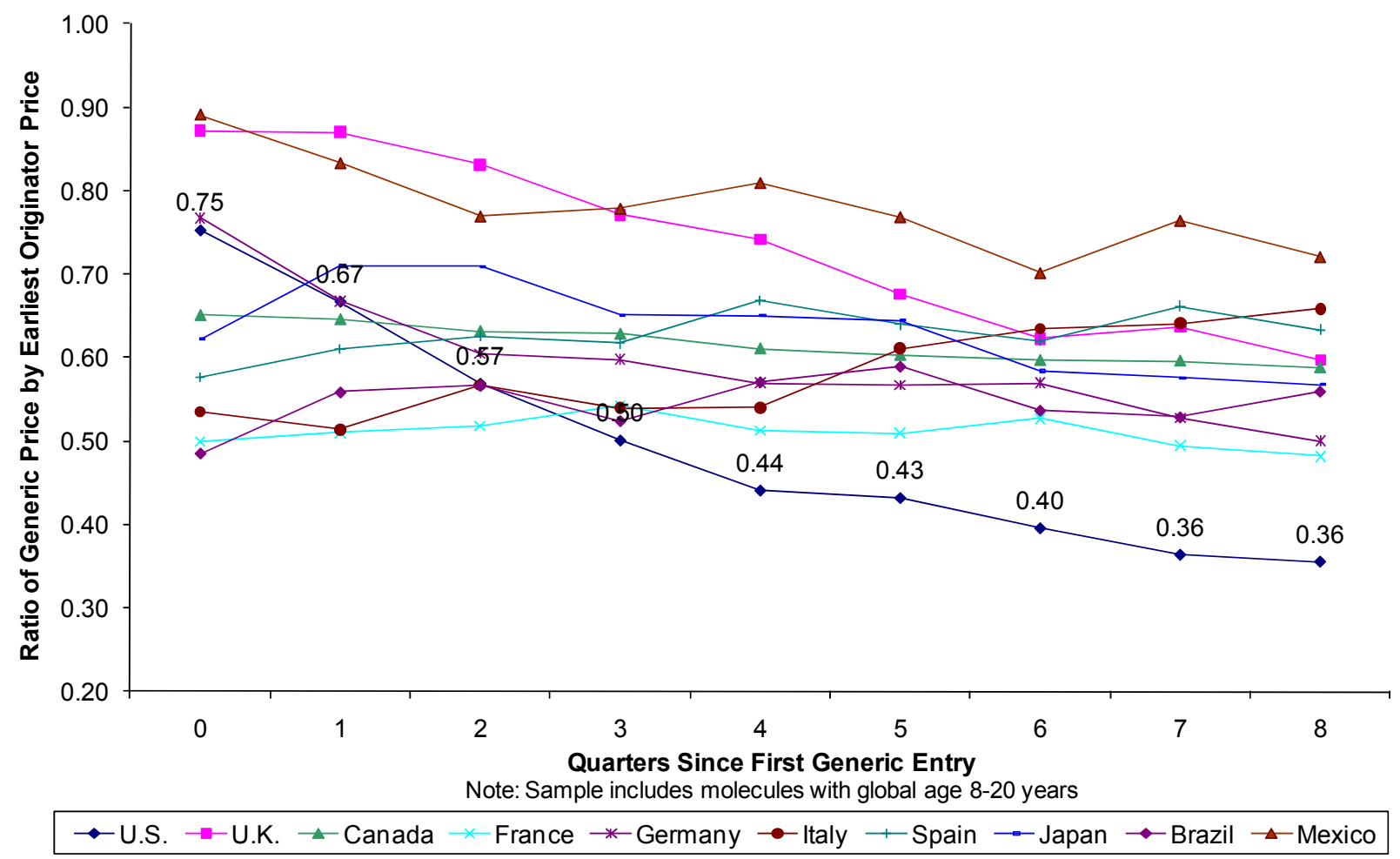


Figure 5: Normalized Originator Price, By Time Since First Generic Entry

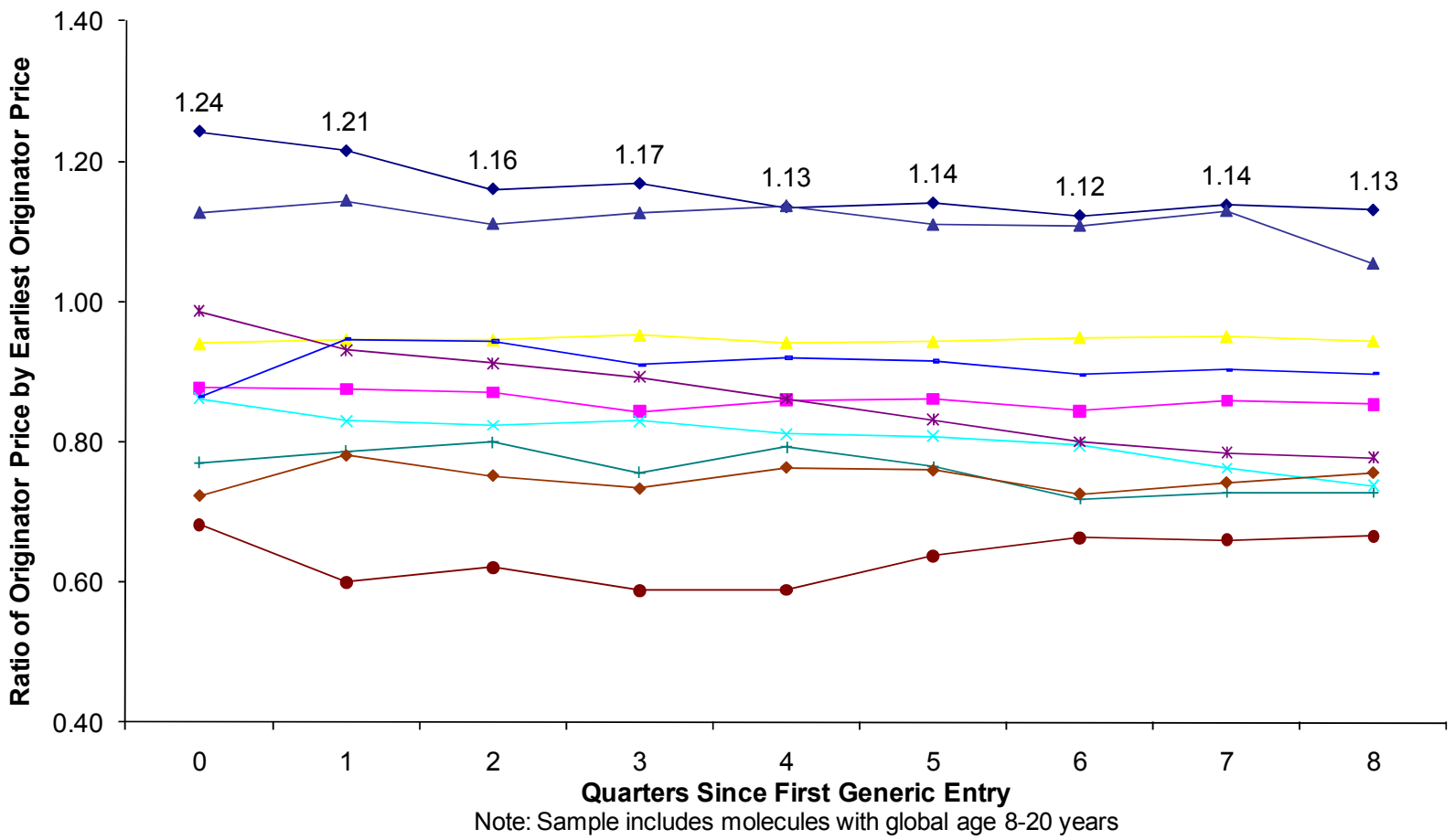

U.S. $\rightarrow$-U.K. $\rightarrow$ Canada $\rightarrow$ France $\rightarrow$ Germany $\rightarrow$ Italy $\rightarrow$ Spain - Japan $\rightarrow$ Brazil $\rightarrow$ Mexico

Figure 6: Generic Share of Volume, By Time Since First Generic Entry

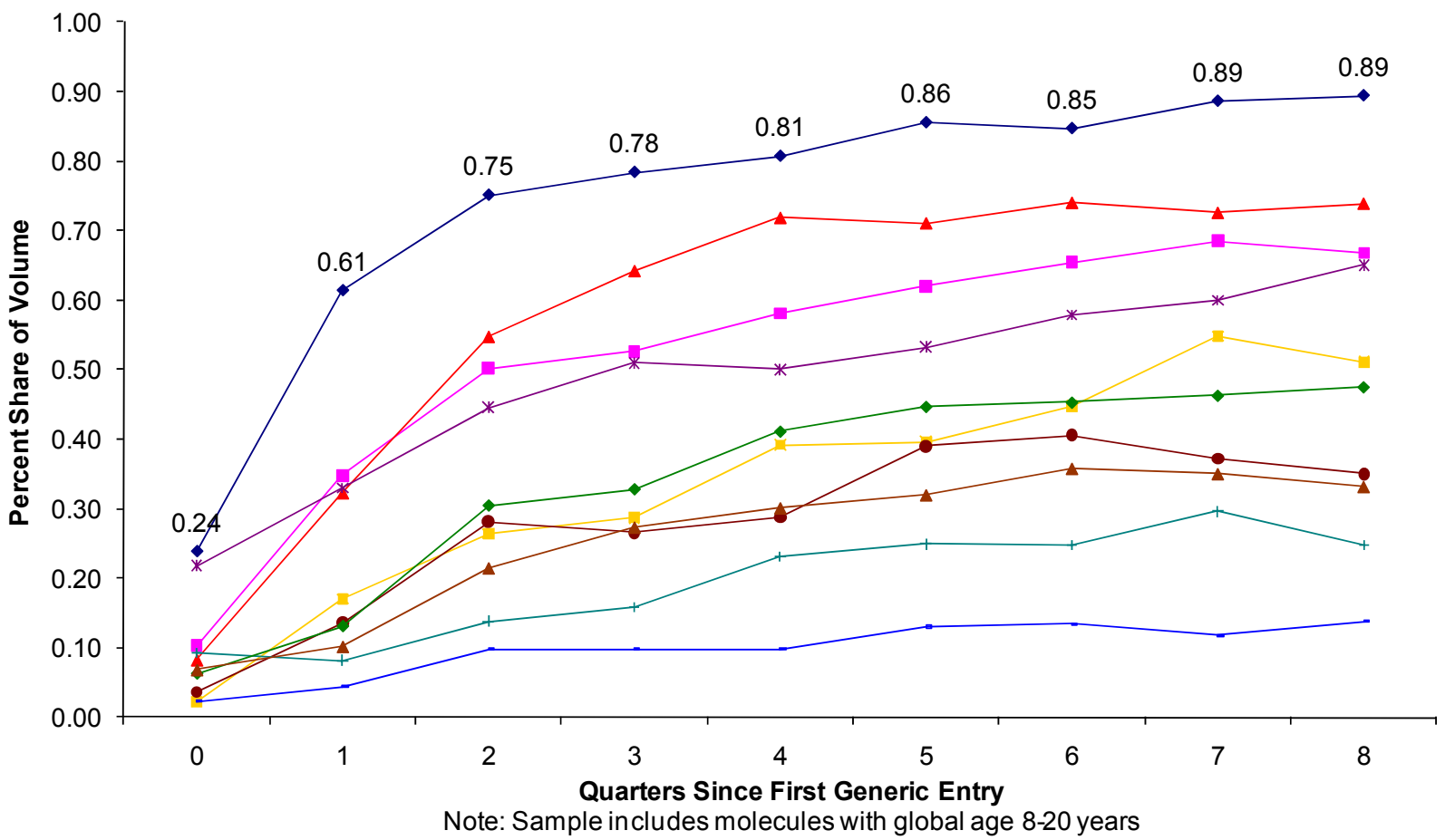

U.S. $\rightarrow$-U.K. $\rightarrow$ Canada $\rightarrow$ France $*$ Germany $\rightarrow$ Italy $\rightarrow$ Spain $\rightarrow$ Japan $\rightarrow$ Brazil $\rightarrow$ Mexico 
Figure 7: Generic Share of Volume, 24 Months Since First Generic Entry

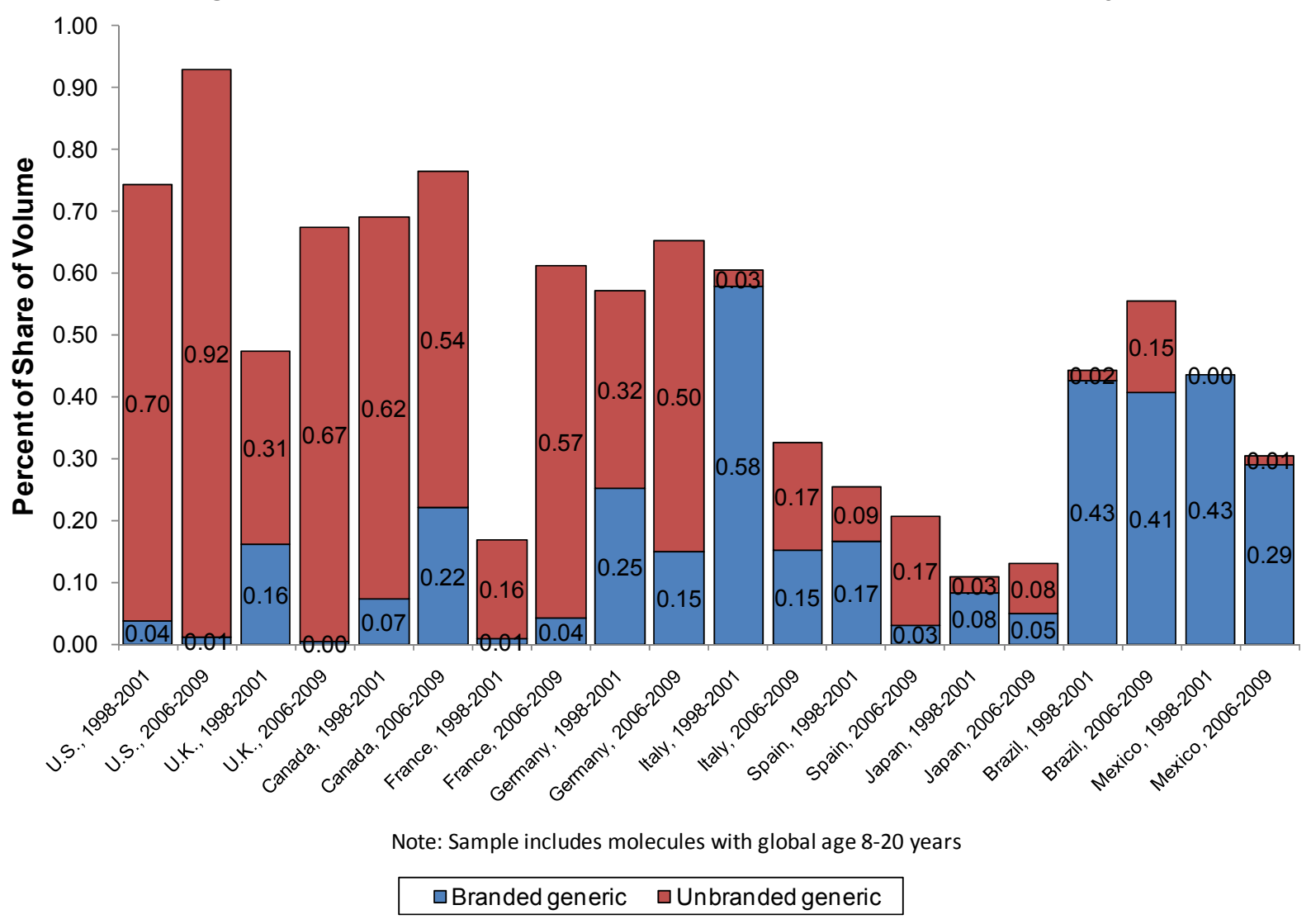


Table 2: Pharmaceutical Sales and Unit Volume

\begin{tabular}{|c|c|c|c|c|c|c|c|c|c|c|}
\hline & U.S. & U.K. & Canada & France & Germany & Italy & Spain & Japan & Brazil & Mexico \\
\hline \multicolumn{11}{|l|}{ Sales } \\
\hline Total market & $\$ 326,438$ & $\$ 24,001$ & $\$ 21,564$ & $\$ 51,742$ & $\$ 52,615$ & $\$ 31,731$ & $\$ 26,375$ & $\$ 111,732$ & $\$ 21,731$ & $\$ 13,992$ \\
\hline Retail market $^{1}$ & 160,840 & 12,165 & 11,701 & 16,672 & 16,218 & 10,135 & 13,410 & 38,239 & 5,877 & 4,260 \\
\hline Generic market & 40,459 & 4,662 & 5,307 & 4,228 & 6,845 & 2,875 & 3,734 & 9,510 & 3,562 & 1,843 \\
\hline Sample cohort ${ }^{2}$ & 83,333 & 3,852 & 3,966 & 5,101 & 4,515 & 2,841 & 3,219 & 14,923 & 797 & 763 \\
\hline Generic market & 6,324 & 615 & 953 & 654 & 1,126 & 264 & 414 & 354 & 354 & 88 \\
\hline & & & & & & & & & & \\
\hline \multicolumn{11}{|l|}{ Unit volume } \\
\hline Total market & 505,325 & 114,274 & 79,097 & 147,957 & 158,167 & 66,998 & 71,519 & 339,007 & 124,123 & 62,118 \\
\hline Retail market $^{1}$ & 170,899 & 45,738 & 31,764 & 39,630 & 39,317 & 28,335 & 35,026 & 135,878 & 20,394 & 7,649 \\
\hline Generic market & 128,555 & 31,540 & 25,500 & 19,264 & 30,357 & 13,125 & 17,246 & 76,733 & 14,424 & 4,627 \\
\hline Sample cohort ${ }^{2}$ & 41,574 & 9,107 & 5,234 & 9,219 & 9,898 & 7,461 & 7,689 & 28,563 & 2,258 & 750 \\
\hline Generic market & 18,215 & 5,150 & 1,991 & 2,260 & 6,313 & 1,212 & 2,223 & 1,545 & 1,331 & 178 \\
\hline \multicolumn{11}{|l|}{ Generic $\%$ sales } \\
\hline Retail market $^{1}$ & 25.2 & 38.3 & 45.4 & 25.4 & 42.2 & 28.4 & 27.8 & 24.9 & 60.6 & 43.3 \\
\hline Sample cohort ${ }^{2}$ & 7.6 & 16.0 & 24.0 & 12.8 & 24.9 & 9.3 & 12.9 & 2.4 & 44.4 & 11.6 \\
\hline \multicolumn{11}{|l|}{ Generic \% volume } \\
\hline Retail market $^{1}$ & 75.2 & 69.0 & 80.3 & 48.6 & 77.2 & 46.3 & 492 & 56.5 & 70.7 & 605 \\
\hline Sample cohort ${ }^{2}$ & 43.8 & 56.5 & 38.0 & 24.5 & 63.8 & 16.2 & 28.9 & 5.4 & 58.9 & 23.8 \\
\hline
\end{tabular}

Sales (\$USD) and unit volume are reported in millions for the 12 months ending June 2009. ${ }^{1}$ Retail market excludes combination products, biologics, OTC, and hospital channel. ${ }^{2}$ Sample cohort includes molecules with global age 8-20 years.

Table 3: Market Size and Generic Entry

\begin{tabular}{|c|c|c|c|c|c|c|c|c|c|c|}
\hline & U.S. & U.K. & Canada & France & Germany & Italy & Spain & Japan & Brazil & Mexico \\
\hline \multicolumn{11}{|c|}{ Per generic manufacturer } \\
\hline Annual sales & 3.99 & 2.88 & 1.11 & 2.00 & 1.02 & 2.66 & 1.96 & 4.03 & 1.87 & 1.16 \\
\hline Price per dose & 0.36 & 0.37 & 0.57 & 0.39 & 0.38 & 0.49 & 0.43 & 0.30 & 0.49 & 1.00 \\
\hline \multicolumn{11}{|c|}{1 generic manufacturer } \\
\hline Annual sales & 2.41 & 2.06 & 1.58 & 2.50 & 5.40 & 5.49 & 3.67 & 1.59 & 2.30 & 1.09 \\
\hline Price per dose & 0.88 & 0.44 & 0.51 & 0.67 & 0.93 & 0.56 & 0.60 & 0.27 & 0.49 & 0.92 \\
\hline \multirow{2}{*}{\multicolumn{11}{|c|}{2 or 3 generic manufacturers }} \\
\hline & & & & & & & & & & \\
\hline Annual sales & 11.02 & 5.22 & 3.25 & 3.94 & 1.76 & 2.24 & 5.72 & 8.27 & 8.39 & 3.01 \\
\hline Price per dose & 0.47 & 0.47 & 0.59 & 0.30 & 0.40 & 0.24 & 0.44 & 0.31 & 0.47 & 1.32 \\
\hline \multicolumn{11}{|c|}{ 4+ generic manufacturers } \\
\hline Annual sales & 34.0 & 18.0 & 6.11 & 20.4 & 11.37 & 13.4 & 16.66 & 50.3 & 5.30 & 6.88 \\
\hline Price per dose & 0.23 & 0.22 & 0.57 & 0.40 & 0.32 & 0.52 & 0.37 & 0.32 & 0.45 & 1.03 \\
\hline
\end{tabular}

$\mathrm{n} / \mathrm{a}$, no cases in sample. Sample includes oral-solid presentations only. 
Table 4: Effects of Market Size on Any Generic Entry and No. of Generic Manufacturers

\begin{tabular}{|c|c|c|c|c|c|c|c|c|c|c|}
\hline \multicolumn{11}{|c|}{ Dependent variable: Any generic entry } \\
\hline & U.S. & U.K. & Canada & France & Germany & Italy & Spain & Japan & Brazil & Mexico \\
\hline InSales & 0.003 & $0.028^{\star \star \star}$ & $0.024^{\star * \star}$ & $0.020^{\star \star \star}$ & $0.043^{\star \star \star}$ & $0.033^{\star \star \star}$ & $0.036^{\star \star *}$ & $0.039^{\star \star \star}$ & $0.055^{\star \star \star}$ & 0.008 \\
\hline \multirow{2}{*}{\multicolumn{11}{|c|}{ Dependent variable: No. of generic manufacturers, conditional on generic entry }} \\
\hline & & & & & & & & & & \\
\hline & U.S. & U.K. & Canada & France & Germany & Italy & Spain & Japan & Brazil & Mexico \\
\hline InSales & $0.715^{\star \star *}$ & $0.340^{\star \star *}$ & $0.566^{\star \star *}$ & $1.588^{\star \star \star}$ & $2.581^{* \star *}$ & $0.663^{\star \star *}$ & $0.981^{* * *}$ & $1.825^{\star \star \star}$ & $1.115^{\star \star *}$ & $0.421^{\star \star \star}$ \\
\hline \multicolumn{11}{|c|}{ Dependent variable: No. of branded generic manufacturers, conditional on generic entry } \\
\hline & U.S. & U.K. & Canada & France & Germany & Italy & Spain & Japan & Brazil & Mexico \\
\hline InSales & 0.003 & 0.017 & $0.211^{\star \star *}$ & $0.223^{\star *}$ & $0.904^{\star \star *}$ & $0.279^{\star \star \star}$ & $0.210^{\star \star}$ & $1.392^{\star \star \star}$ & $0.937^{\star \star \star}$ & $0.397^{\star * \star}$ \\
\hline \multicolumn{11}{|c|}{ Dependent variable: No. of unbranded generic manufacturers, conditional on generic entry } \\
\hline & U.S. & U.K. & Canada & France & Germany & Italy & Spain & Japan & Brazil & Mexico \\
\hline InSales & $0.712^{\star \star \star}$ & $0.312^{\star \star \star}$ & $0.352^{* * *}$ & $1.437^{* * *}$ & $1.804^{* * *}$ & $1.124^{\star \star}$ & $1.196^{* * *}$ & $0.501^{* * *}$ & $0.338^{\star * *}$ & $0.083^{* *}$ \\
\hline & & & & & & & & & & \\
\hline
\end{tabular}

Marginal effects from Probit and Negative-Binomial regressions, clustered by molecule; robust standard errors in brackets, significant at ${ }^{* * *} p<0.01,{ }^{* *} p<0.05,{ }^{*} p<0.10$

Table 5: Effects of No. of Generic Manufacturers on Normalized Generic and Originator Price

Dependent variable: Normalized generic price

\begin{tabular}{|c|c|c|c|c|c|c|c|c|c|c|}
\hline & U.S. & U.K. & Canada & France & Germany & Italy & Spain & Japan & Brazil & Mexico \\
\hline GenMfrBrand & 0.029 & $-0.097^{\star * \star}$ & $-0.014^{\star \star}$ & -0.014 & $-0.009^{* *}$ & 0.002 & -0.006 & $-0.010^{\star \star \star}$ & $-0.006^{\star \star}$ & $0.038^{*}$ \\
\hline GenMfrUnbr & $-0.043^{* * *}$ & $-0.076^{\star * *}$ & $-0.011^{\star *}$ & -0.006 & $-0.015^{\star \star *}$ & $-0.043^{* * *}$ & $-0.013^{* \star *}$ & 0.001 & $-0.012^{* *}$ & $-0.080^{* *}$ \\
\hline & & & & & & & & & & \\
\hline \multicolumn{11}{|c|}{ Dependent variable: Normalized originator price } \\
\hline & U.S. & U.K. & Canada & France & Germany & Italy & Spain & Japan & Brazil & Mexico \\
\hline GenMfrBrand & 0.107 & -0.024 & $-0.020^{* *}$ & -0.001 & $-0.017^{*}$ & 0.000 & -0.002 & $-0.004^{* \star *}$ & $-0.010^{* \star *}$ & 0.005 \\
\hline GenMfrUnbr & $-0.006^{*}$ & -0.004 & -0.001 & $-0.013^{* * *}$ & -0.006 & $-0.031^{* * *}$ & $-0.017^{* * *}$ & $-0.003^{* * *}$ & $-0.010^{*}$ & -0.010 \\
\hline
\end{tabular}

Marginal effects from OLS regressions, clustered by molecule; robust standard errors in brackets, significant at ${ }^{* \star *} p<0.01,{ }^{* *} p<0.05$,

Table 6: Effects of Normalized Generic Price on Generic Share of Volume Dependent variable: Generic share of volume

\begin{tabular}{|c|c|c|c|c|c|c|c|c|c|c|}
\hline \multicolumn{11}{|c|}{ Dependent varıable: Generıc share of volume } \\
\hline & U.S. & U.K. & Canada & France & Germany & Italy & Spain & Japan & Brazil & Mexico \\
\hline GenPrice $^{1}$ & $-0.144^{\star \star *}$ & $-0.228^{\star \star *}$ & $-0.382^{\star \star *}$ & $-0.262^{*}$ & $-0.202^{\star \star}$ & 0.039 & -0.068 & 0.050 & $-0.346^{\star \star *}$ & $0.140^{\star *}$ \\
\hline GenPrice $^{2}$ & $-0.207^{* * *}$ & $-0.224^{* * *}$ & $-1.111^{* * *}$ & $-0.425^{\star *}$ & $-0.371^{* * *}$ & 0.002 & -0.019 & 0.038 & $\mathrm{n} / \mathrm{a}$ & $\mathrm{n} / \mathrm{a}$ \\
\hline
\end{tabular}

Marginal effects from ${ }^{1}$ OLS and ${ }^{2}$ 2SLS-GMM regressions, clustered by molecule; robust standard errors in brackets, significant at ${ }^{* * *} p<0.01,{ }^{* *} p<0.05,{ }^{*} p<0.10 . n / a$, instrumental variables not available. 
Table 7: Summary Effects of Policy Changes for Years 2007-2009, Relative to Years 1998-2001 Dependent variable: Any generic entry

\begin{tabular}{|c|c|c|c|c|c|c|c|c|c|c|}
\hline \multicolumn{11}{|c|}{ Dependent variable: Any generic entry } \\
\hline & U.S. & U.K. & Canada & France & Germany & Italy & Spain & Japan & Brazil & Mexico \\
\hline Years 2006-2009 & $0.147^{* * *}$ & $0.091^{* * *}$ & -0.008 & $0.097^{* * *}$ & $0.071^{* *}$ & -0.046 & $-0.133^{\star * *}$ & 0.046 & -0.043 & -0.012 \\
\hline \multicolumn{11}{|c|}{ Dependent variable: No. of generic manufacturers, conditional on generic entry } \\
\hline & U.S. & U.K. & Canada & France & Germany & Italy & Spain & Japan & Brazil & Mexico \\
\hline Years 2006-2009 & 0.385 & -0.199 & 0.497 & $3.803^{* \star \star}$ & $2.612^{\star *}$ & $1.867^{* \star}$ & $1.739^{*}$ & -0.347 & $1.479^{\star \star \star}$ & $0.570^{*}$ \\
\hline \multicolumn{11}{|c|}{ Dependent variable: No. of branded generic manufacturers, conditional on generic entry } \\
\hline & U.S. & U.K. & Canada & France & Germany & Italy & Spain & Japan & Brazil & Mexico \\
\hline Years 2006-2009 & 0.039 & $-0.237^{* * *}$ & $0.652^{*}$ & -0.497 & $-1.125^{\star *}$ & $-0.785^{\star * *}$ & $-1.448^{* * *}$ & $-2.325^{* * *}$ & 0.034 & $0.601^{*}$ \\
\hline \multicolumn{11}{|c|}{ Dependent variable: No. of unbranded generic manufacturers, conditional on generic entry } \\
\hline & U.S. & U.K. & Canada & France & Germany & Italy & Spain & Japan & Brazil & Mexico \\
\hline Years 2006-2009 & 0.352 & 0.183 & -0.023 & $4.472^{\star \star \star}$ & $3.855^{\star \star \star}$ & $8.680^{* \star *}$ & $7.618^{\star \star *}$ & $2.738^{\star \star *}$ & $4.434^{\star \star \star}$ & 0.057 \\
\hline \multicolumn{11}{|c|}{ Dependent variable: Normalized generic price } \\
\hline & U.S. & U.K. & Canada & France & Germany & Italy & Spain & Japan & Brazil & Mexico \\
\hline Years 2006-2009 & 0.011 & $-0.331^{* * *}$ & $-0.092^{* * *}$ & $-0.250^{* * *}$ & $-0.151^{* * *}$ & $-0.298^{* * *}$ & $-0.277^{* * *}$ & $-0.128^{* * *}$ & $-0.273^{\star * *}$ & $-0.129^{* *}$ \\
\hline \multicolumn{11}{|c|}{ Dependent variable: Normalized originator price } \\
\hline & U.S. & U.K. & Canada & France & Germany & Italy & Spain & Japan & Brazil & Mexico \\
\hline Years 2006-2009 & $0.044^{* *}$ & $-0.139^{* * *}$ & -0.007 & $-0.149^{* \star *}$ & $-0.156^{\star \star \star}$ & $-0.279^{* * *}$ & $-0.221^{* * *}$ & $-0.169^{* \star *}$ & $-0.176^{\star \star *}$ & $0.047^{* *}$ \\
\hline \multicolumn{11}{|c|}{ Dependent variable: Generic share of volume } \\
\hline & U.S. & U.K. & Canada & France & Germany & Italy & Spain & Japan & Brazil & Mexico \\
\hline Years 2006-2009 & $0.182^{* * *}$ & $0.155^{\star \star *}$ & 0.010 & $0.188^{* * *}$ & 0.001 & -0.046 & -0.021 & $0.033^{*}$ & $0.181^{* * *}$ & 0.070 \\
\hline \multicolumn{11}{|c|}{ Dependent variable: Branded generic share of volume } \\
\hline & U.S. & U.K. & Canada & France & Germany & Italy & Spain & Japan & Brazil & Mexico \\
\hline Years 2006-2009 & 0.008 & 0.014 & 0.046 & $0.036^{* *}$ & -0.018 & -0.033 & 0.049 & 0.014 & $0.090^{*}$ & 0.032 \\
\hline \multicolumn{11}{|c|}{ Dependent variable: Unbranded generic share of volume } \\
\hline & U.S. & U.K. & Canada & France & Germany & Italy & Spain & Japan & Brazil & Mexico \\
\hline Years 2006-2009 & $0.174^{* * *}$ & $0.141^{* *}$ & -0.035 & $0.152^{* * *}$ & 0.019 & -0.014 & $-0.070^{\star *}$ & $0.019^{\star \star *}$ & $0.090^{* *}$ & $0.038^{\star \star *}$ \\
\hline
\end{tabular}


Table 8: Savings from Generics

\begin{tabular}{|c|c|c|c|c|c|c|c|c|c|c|}
\hline \multicolumn{11}{|c|}{ Percent savings in prices } \\
\hline & U.S. & U.K. & Canada & France & Germany & Italy & Spain & Japan & Brazil & Mexico \\
\hline P1: Years 1998-2001 & 4.439 & 0.556 & 1.358 & 0.578 & 1.109 & 0.085 & 0.375 & 0.750 & 0.490 & 0.222 \\
\hline P2: Years 2002-2005 & 3.051 & 0.798 & 0.718 & 0.648 & 0.710 & 0.135 & 0.326 & 0.658 & 0.927 & 0.355 \\
\hline P3: Years 2006-2009 & 4.554 & 4.091 & 0.796 & 0.790 & 0.807 & 0.148 & 0.192 & 0.664 & 1.353 & 1.194 \\
\hline$\%$ diff. P3-P1 & 0.115 & 3.535 & -0.562 & 0.212 & -0.302 & 0.063 & -0.183 & -0.085 & 0.863 & 0.973 \\
\hline \multicolumn{11}{|c|}{ Percent share of unit volume } \\
\hline & U.S. & U.K. & Canada & France & Germany & Italy & Spain & Japan & Brazil & Mexico \\
\hline P1: Years 1998-2001 & 0.372 & 0.430 & 0.463 & 0.070 & 0.562 & 0.234 & 0.440 & 0.033 & 0.364 & 0.254 \\
\hline P2: Years 2002-2005 & 0.542 & 0.635 & 0.659 & 0.302 & 0.662 & 0.231 & 0.408 & 0.044 & 0.608 & 0.291 \\
\hline P3: Years 2006-2009 & 0.521 & 0.664 & 0.691 & 0.549 & 0.621 & 0.240 & 0.393 & 0.064 & 0.719 & 0.285 \\
\hline$\%$ diff. P3-P1 & 0.150 & 0.234 & 0.228 & 0.479 & 0.059 & 0.007 & -0.047 & 0.031 & 0.355 & 0.031 \\
\hline \multicolumn{11}{|c|}{ Total percent savings from generics, for the $8-20$ year cohort } \\
\hline & U.S. & U.K. & Canada & France & Germany & Italy & Spain & Japan & Brazil & Mexico \\
\hline P1: Years 1998-2001 & 1.651 & 0.239 & 0.629 & 0.041 & 0.623 & 0.020 & 0.165 & 0.025 & 0.178 & 0.056 \\
\hline P2: Years 2002-2005 & 1.655 & 0.507 & 0.473 & 0.196 & 0.470 & 0.031 & 0.133 & 0.029 & 0.564 & 0.103 \\
\hline P3: Years 2006-2009 & 2.375 & 2.715 & 0.550 & 0.433 & 0.501 & 0.036 & 0.076 & 0.043 & 0.972 & 0.340 \\
\hline$\%$ diff. P3-P1 & 0.724 & 2.476 & -0.079 & 0.393 & -0.122 & 0.016 & -0.090 & 0.018 & 0.794 & 0.284 \\
\hline \multicolumn{11}{|c|}{ Total percent savings from generics, relative to total market } \\
\hline & U.S. & U.K. & Canada & France & Germany & Italy & Spain & Japan & Brazil & Mexico \\
\hline P1: Years 1998-2001 & 0.025 & 0.008 & 0.048 & 0.001 & 0.052 & 0.002 & 0.032 & 0.002 & 0.028 & 0.004 \\
\hline P2: Years 2002-2005 & 0.065 & 0.061 & 0.035 & 0.010 & 0.062 & 0.003 & 0.018 & 0.003 & 0.079 & 0.007 \\
\hline P3: Years 2006-2009 & 0.201 & 0.235 & 0.053 & 0.029 & 0.049 & 0.003 & 0.007 & 0.005 & 0.063 & 0.020 \\
\hline$\%$ diff. P3-P1 & 0.176 & 0.227 & 0.005 & 0.028 & -0.003 & 0.001 & -0.026 & 0.003 & 0.035 & 0.016 \\
\hline
\end{tabular}


Appendix Table 1: Descriptive Statistics

\begin{tabular}{|c|c|c|c|c|c|}
\hline U.S. & $\mathrm{N}$ & Mean & STD & Min & Max \\
\hline GenMfr & 24,595 & 1.05 & 2.67 & 0 & 23 \\
\hline GenMfrBrand & 24,595 & 0.02 & 0.13 & 0 & 1 \\
\hline GenMfrUnbr. & 24,595 & 1.04 & 2.65 & 0 & 23 \\
\hline GenPrice & 354 & 0.77 & 0.43 & 0.08 & 1.88 \\
\hline OrigPrice & 4,751 & 1.14 & 0.34 & 0.02 & 2.47 \\
\hline GenShare & 5,665 & 0.84 & 0.24 & 0.0000003 & 1.00 \\
\hline Sales & 24,595 & $137,524,067$ & $359,636,059$ & 128 & $5,301,822,792$ \\
\hline Licensees & 24,595 & 0.42 & 0.50 & 0 & 2 \\
\hline OrigForms & 24,595 & 0.58 & 0.85 & 0 & 4 \\
\hline OTC share & 24,595 & 0.80 & 8.85 & 0 & 100.00 \\
\hline Hosp. share & 24,595 & 22.37 & 32.57 & 0 & 99.98 \\
\hline Ext. release & 24,595 & 0.06 & 0.24 & 0 & 1 \\
\hline IV form & 24,595 & 0.20 & 0.40 & 0 & 1 \\
\hline Topical form & 24,595 & 0.04 & 0.19 & 0 & 1 \\
\hline Other form & 24,595 & 0.15 & 0.36 & 0 & 1 \\
\hline Global age & 24,595 & 163.82 & 41.41 & 96 & 240 \\
\hline Molecule lag & 24,572 & 24.72 & 32.18 & 0 & 204 \\
\hline GenAge & 5,665 & 39.93 & 31.47 & 0 & 169 \\
\hline Global avail. & 24,595 & 0.45 & 0.50 & 0 & 1 \\
\hline U.K. & $\mathrm{N}$ & Mean & STD & Min & Max \\
\hline GenMfr & 19,554 & 0.40 & 1.00 & 0 & 7 \\
\hline GenMfrBrand & 19,554 & 0.04 & 0.24 & 0 & 3 \\
\hline GenMfrUnbr. & 19,554 & 0.36 & 0.89 & 0 & 6 \\
\hline GenPrice & 661 & 0.54 & 0.32 & 0.01 & 1.00 \\
\hline OrigPrice & 3,207 & 0.84 & 0.15 & 0.16 & 1.18 \\
\hline GenShare & 3,580 & 0.62 & 0.32 & 0.000004 & 1.00 \\
\hline Sales & 19,554 & $11,488,867$ & $28,129,153$ & 5 & $383,365,491$ \\
\hline Licensees & 19,554 & 0.29 & 0.48 & 0 & 2 \\
\hline OrigForms & 19,554 & 0.86 & 1.03 & 0 & 4 \\
\hline OTC share & 19,554 & 0.80 & 8.44 & 0 & 100.00 \\
\hline Hosp. share & 19,554 & 26.40 & 36.91 & 0 & 100.00 \\
\hline Ext. release & 19,554 & 0.04 & 0.20 & 0 & 1 \\
\hline IV form & 19,554 & 0.12 & 0.33 & 0 & 1 \\
\hline Topical form & 19,554 & 0.04 & 0.19 & 0 & 1 \\
\hline Other form & 19,554 & 0.16 & 0.37 & 0 & 1 \\
\hline Global age & 19,554 & 163.65 & 40.64 & 96 & 240 \\
\hline Molecule lag & 19,554 & 19.23 & 31.78 & 0 & 213 \\
\hline GenAge & 3,579 & 36.38 & 26.82 & 0 & 152 \\
\hline Global avail. & 19,554 & 0.52 & 0.50 & 0 & 1 \\
\hline
\end{tabular}


Appendix Table 1: Descriptive Statistics (Continued)

\begin{tabular}{lrrrrr} 
Canada & $\mathrm{N}$ & Mean & STD & Min & Max \\
\hline GenMfr & 15,723 & 0.97 & 2.16 & 0 & 12 \\
GenMfrBrand & 15,723 & 0.33 & 0.99 & 0 & 6 \\
GenMfrUnbr. & 15,723 & 0.65 & 1.53 & 0 & 9 \\
GenPrice & 2,227 & 0.58 & 0.13 & 0.18 & 1.19 \\
OrigPrice & 3,524 & 0.91 & 0.15 & 0.03 & 2.10 \\
GenShare & 4,137 & 0.71 & 0.30 & 0.000007 & 1.00 \\
Sales & 15,723 & $11,220,881$ & $29,250,230$ & 13 & $360,446,191$ \\
Licensees & 15,723 & 0.28 & 0.46 & 0 & 2 \\
OrigForms & 15,723 & 0.43 & 0.76 & 0 & 4 \\
OTC share & 15,723 & 0.06 & 2.52 & 0 & 100.00 \\
Hosp. share & 15,723 & 16.94 & 29.19 & 0 & 100.00 \\
Ext. release & 15,723 & 0.06 & 0.23 & 0 & 1 \\
IV form & 15,723 & 0.10 & 0.30 & 0 & 1 \\
Topical form & 15,723 & 0.05 & 0.21 & 0 & 1 \\
Other form & 15,723 & 0.17 & 0.37 & 0 & 1 \\
Global age & 15,723 & 162.85 & 40.80 & 96 & 240 \\
Molecule lag & 15,723 & 31.79 & 30.56 & 0 & 224 \\
GenAge & 3,997 & 52.37 & 37.43 & 0 & 158 \\
Global avail. & 15,723 & 0.56 & 0.50 & 0 & 1 \\
\hline
\end{tabular}

\begin{tabular}{lrrrrr}
\hline France & \multicolumn{1}{c}{$\mathrm{N}$} & Mean & STD & Min & Max \\
\hline GenMfr & 14,510 & 0.66 & 2.40 & 0 & 16 \\
GenMfrBrand & 14,510 & 0.07 & 0.38 & 0 & 4 \\
GenMfrUnbr. & 14,510 & 0.59 & 2.22 & 0 & 16 \\
GenPrice & 506 & 0.65 & 0.34 & 0.18 & 2.37 \\
OrigPrice & 1,460 & 0.78 & 0.16 & 0.35 & 1.05 \\
GenShare & 1,590 & 0.41 & 0.33 & 0.0000004 & 1.00 \\
Sales & 13,296 & $20,115,626$ & $48,705,099$ & 33 & $726,745,404$ \\
Licensees & 14,510 & 0.42 & 0.56 & 0 & 2 \\
OrigForms & 14,510 & 0.38 & 0.72 & 0 & 3 \\
OTC share & 14,510 & 0.48 & 6.74 & 0 & 100.00 \\
Hosp. share & 14,510 & 10.55 & 21.19 & 0 & 100.00 \\
Ext. release & 14,510 & 0.04 & 0.19 & 0 & 1 \\
IV form & 14,510 & 0.04 & 0.19 & 0 & 1 \\
Topical form & 14,510 & 0.06 & 0.23 & 0 & 1 \\
Other form & 14,510 & 0.18 & 0.38 & 0 & 1 \\
Global age & 14,510 & 167.34 & 40.79 & 96 & 240 \\
Molecule lag & 14,510 & 32.39 & 36.29 & 0 & 210 \\
GenAge & 1,574 & 25.42 & 17.85 & 0 & 101 \\
Global avail. & 14,510 & 0.47 & 0.50 & 0 & 1 \\
\hline
\end{tabular}




\begin{tabular}{|c|c|c|c|c|c|}
\hline \multicolumn{6}{|c|}{ Appendix Table 1: Descriptive Statistics (Continued) } \\
\hline Germany & $\mathrm{N}$ & Mean & STD & Min & Max \\
\hline GenMfr & 24,390 & 2.02 & 5.52 & 0 & 41 \\
\hline GenMfrBrand & 24,390 & 0.70 & 2.21 & 0 & 30 \\
\hline GenMfrUnbr. & 24,390 & 1.34 & 3.82 & 0 & 34 \\
\hline GenPrice & 4,092 & 0.54 & 0.29 & 0.01 & 1.25 \\
\hline OrigPrice & 4,379 & 0.78 & 0.28 & 0.07 & 1.82 \\
\hline GenShare & 5,203 & 0.65 & 0.32 & 0.000003 & 1.00 \\
\hline Sales & 24,390 & $11,731,786$ & $27,256,808$ & 10 & $534,265,566$ \\
\hline Licensees & 24,390 & 0.86 & 1.67 & 0 & 13 \\
\hline OrigForms & 24,390 & 0.92 & 1.05 & 0 & 5 \\
\hline OTC share & 24,390 & 1.90 & 13.55 & 0 & 100.00 \\
\hline Hosp. share & 24,390 & 17.19 & 30.46 & 0 & 99.99 \\
\hline Ext. release & 24,390 & 0.04 & 0.20 & 0 & 1 \\
\hline IV form & 24,390 & 0.18 & 0.38 & 0 & 1 \\
\hline Topical form & 24,390 & 0.05 & 0.22 & 0 & 1 \\
\hline Other form & 24,390 & 0.16 & 0.37 & 0 & 1 \\
\hline Global age & 24,390 & 166.55 & 41.33 & 96 & 240 \\
\hline Molecule lag & 24,390 & 22.87 & 29.40 & 0 & 225 \\
\hline GenAge & 4,994 & 45.41 & 34.06 & 0 & 169 \\
\hline Global avail. & 24,390 & 0.41 & 0.49 & 0 & 1 \\
\hline Italy & $\mathrm{N}$ & Mean & STD & Min & Max \\
\hline GenMfr & 19,881 & 0.55 & 2.58 & 0 & 41 \\
\hline GenMfrBrand & 19,881 & 0.29 & 1.48 & 0 & 32 \\
\hline GenMfrUnbr. & 19,881 & 0.26 & 1.49 & 0 & 17 \\
\hline GenPrice & 2,552 & 0.83 & 0.27 & 0.13 & 1.60 \\
\hline OrigPrice & 2,722 & 0.80 & 0.27 & 0.13 & 1.44 \\
\hline GenShare & 3,290 & 0.41 & 0.35 & 0.000002 & 1.00 \\
\hline Sales & 19,881 & $11,712,076$ & $25,519,945$ & 6 & $244,190,237$ \\
\hline Licensees & 19,881 & 0.76 & 0.87 & 0 & 4 \\
\hline OrigForms & 19,881 & 0.40 & 0.72 & 0 & 3 \\
\hline OTC share & 19,881 & 3.07 & 16.86 & 0 & 100.00 \\
\hline Hosp. share & 19,881 & 8.15 & 19.51 & 0 & 99.99 \\
\hline Ext. release & 19,881 & 0.04 & 0.19 & 0 & 1 \\
\hline IV form & 19,881 & 0.08 & 0.27 & 0 & 1 \\
\hline Topical form & 19,881 & 0.06 & 0.24 & 0 & 1 \\
\hline Other form & 19,881 & 0.24 & 0.43 & 0 & 1 \\
\hline Global age & 19,881 & 170.00 & 40.61 & 96 & 240 \\
\hline Molecule lag & 19,881 & 31.31 & 33.07 & 0 & 179 \\
\hline GenAge & 3,290 & 110.32 & 63.35 & 0 & 239 \\
\hline Global avail. & 19,881 & 0.41 & 0.49 & 0 & 1 \\
\hline
\end{tabular}


Appendix Table 1: Descriptive Statistics (Continued)

\begin{tabular}{|c|c|c|c|c|c|}
\hline Spain & $\mathrm{N}$ & Mean & STD & Min & Max \\
\hline GenMfr & 19,481 & 1.50 & 4.50 & 0 & 52 \\
\hline GenMfrBrand & 19,481 & 0.56 & 1.81 & 0 & 19 \\
\hline GenMfrUnbr. & 19,481 & 0.97 & 3.41 & 0 & 38 \\
\hline GenPrice & 4,319 & 0.72 & 0.23 & 0.05 & 1.12 \\
\hline OrigPrice & 4,988 & 0.75 & 0.21 & 0.06 & 1.05 \\
\hline GenShare & 5,775 & 0.45 & 0.34 & 0.000005 & 1.00 \\
\hline Sales & 19,481 & $9,847,623$ & $20,464,211$ & 5 & $286,687,223$ \\
\hline Licensees & 19,481 & 0.66 & 0.78 & 0 & 4 \\
\hline OrigForms & 19,481 & 0.43 & 0.75 & 0 & 3 \\
\hline OTC share & 19,481 & 0.35 & 5.56 & 0 & 100.00 \\
\hline Hosp. share & 19,481 & 9.62 & 25.04 & 0 & 100.00 \\
\hline Ext. release & 19,481 & 0.04 & 0.19 & 0 & 1 \\
\hline IV form & 19,481 & 0.08 & 0.26 & 0 & 1 \\
\hline Topical form & 19,481 & 0.07 & 0.26 & 0 & 1 \\
\hline Other form & 19,481 & 0.21 & 0.41 & 0 & 1 \\
\hline Global age & 19,481 & 166.81 & 40.66 & 96 & 240 \\
\hline Molecule lag & 19,481 & 37.69 & 34.16 & 0 & 202 \\
\hline GenAge & 5,775 & 108.80 & 59.05 & 0 & 239 \\
\hline Global avail. & 19,481 & 0.48 & 0.50 & 0 & 1 \\
\hline Japan & $\mathrm{N}$ & Mean & STD & Min & Max \\
\hline GenMfr & 24,692 & 1.31 & 3.71 & 0 & 36 \\
\hline GenMfrBrand & 24,692 & 1.00 & 2.92 & 0 & 28 \\
\hline GenMfrUnbr. & 24,692 & 0.33 & 1.70 & 0 & 36 \\
\hline GenPrice & 5,061 & 0.56 & 0.19 & 0.08 & 1.05 \\
\hline OrigPrice & 5,526 & 0.91 & 0.11 & 0.60 & 1.12 \\
\hline GenShare & 5,963 & 0.15 & 0.26 & 0.000004 & 1.00 \\
\hline Sales & 24,690 & $36,489,426$ & $89,855,117$ & 34 & $1,429,952,122$ \\
\hline Licensees & 24,692 & 0.55 & 0.69 & 0 & 6 \\
\hline OrigForms & 24,692 & 0.45 & 0.83 & 0 & 5 \\
\hline OTC share & 24,692 & 0.63 & 7.34 & 0 & 100.00 \\
\hline Hosp. share & 24,692 & 41.77 & 29.06 & 0 & 99.96 \\
\hline Ext. release & 24,692 & 0.03 & 0.16 & 0 & 1 \\
\hline IV form & 24,692 & 0.20 & 0.40 & 0 & 1 \\
\hline Topical form & 24,692 & 0.05 & 0.23 & 0 & 1 \\
\hline Other form & 24,692 & 0.09 & 0.28 & 0 & 1 \\
\hline Global age & 24,692 & 171.69 & 40.91 & 96 & 240 \\
\hline Molecule lag & 24,692 & 24.13 & 37.52 & 0 & 211 \\
\hline GenAge & 5,666 & 52.09 & 37.40 & 0 & 177 \\
\hline Global avail. & 24,692 & 0.27 & 0.44 & 0 & 1 \\
\hline
\end{tabular}




\begin{tabular}{|c|c|c|c|c|c|}
\hline \multicolumn{6}{|c|}{ Appendix Table 1: Descriptive Statistics (Continued) } \\
\hline Brazil & $\mathrm{N}$ & Mean & STD & Min & Max \\
\hline GenMfr & 15,826 & 1.47 & 3.53 & 0 & 38 \\
\hline GenMfrBrand & 15,826 & 1.10 & 2.80 & 0 & 33 \\
\hline GenMfrUnbr. & 15,826 & 0.47 & 1.46 & 0 & 15 \\
\hline GenPrice & 4,076 & 0.48 & 0.23 & 0.03 & 1.15 \\
\hline OrigPrice & 4,239 & 0.68 & 0.19 & 0.14 & 1.23 \\
\hline GenShare & 6,115 & 0.67 & 0.35 & 0.0003 & 1.00 \\
\hline Sales & 15,826 & $3,518,583$ & $7,132,281$ & 409 & $78,588,090$ \\
\hline Licensees & 15,826 & 0.29 & 0.50 & 0 & 2 \\
\hline OrigForms & 15,826 & 0.24 & 0.51 & 0 & 3 \\
\hline OTC share & 15,826 & 0.42 & 6.21 & 0 & 100.00 \\
\hline Hosp. share & $\mathrm{n} / \mathrm{a}$ & $\mathrm{n} / \mathrm{a}$ & $\mathrm{n} / \mathrm{a}$ & $\mathrm{n} / \mathrm{a}$ & $n / a$ \\
\hline Ext. release & 15,826 & 0.05 & 0.21 & 0 & 1 \\
\hline IV form & 15,826 & 0.15 & 0.36 & 0 & 1 \\
\hline Topical form & 15,826 & 0.05 & 0.21 & 0 & 1 \\
\hline Other form & 15,826 & 0.17 & 0.38 & 0 & 1 \\
\hline Global age & 15,826 & 165.97 & 40.70 & 96 & 240 \\
\hline Molecule lag & 15,804 & 46.04 & 37.10 & 0 & 189 \\
\hline GenAge & 6,115 & 89.02 & 47.69 & 0 & 214 \\
\hline Global avail. & 15,826 & 0.49 & 0.50 & 0 & 1 \\
\hline Mexico & $\mathrm{N}$ & Mean & STD & Min & $\operatorname{Max}$ \\
\hline GenMfr & 16,437 & 0.66 & 1.98 & 0 & 28 \\
\hline GenMfrBrand & 16,437 & 0.60 & 1.76 & 0 & 23 \\
\hline GenMfrUnbr. & 16,437 & 0.10 & 0.53 & 0 & 10 \\
\hline GenPrice & 2,738 & 0.82 & 0.36 & 0.11 & 3.70 \\
\hline OrigPrice & 2,568 & 1.07 & 0.27 & 0.32 & 1.96 \\
\hline GenShare & 3,726 & 0.50 & 0.40 & 0.000009 & 1.00 \\
\hline Sales & 16,437 & $2,392,473$ & $4,593,691$ & 3 & $43,338,891$ \\
\hline Licensees & 16,437 & 0.32 & 0.51 & 0 & 4 \\
\hline OrigForms & 16,437 & 0.40 & 0.78 & 0 & 4 \\
\hline OTC share & 16,437 & 0.55 & 6.87 & 0 & 100.00 \\
\hline Hosp. share & $\mathrm{n} / \mathrm{a}$ & $\mathrm{n} / \mathrm{a}$ & $\mathrm{n} / \mathrm{a}$ & $\mathrm{n} / \mathrm{a}$ & $n / a$ \\
\hline Ext. release & 16,437 & 0.03 & 0.18 & 0 & 1 \\
\hline IV form & 16,437 & 0.14 & 0.35 & 0 & 1 \\
\hline Topical form & 16,437 & 0.06 & 0.24 & 0 & 1 \\
\hline Other form & 16,437 & 0.20 & 0.40 & 0 & 1 \\
\hline Global age & 16,437 & 166.74 & 40.82 & 96 & 240 \\
\hline Molecule lag & 16,437 & 39.69 & 39.63 & 0 & 231 \\
\hline GenAge & 3,726 & 89.26 & 56.57 & 0 & 222 \\
\hline Global avail. & 16,437 & 0.44 & 0.50 & 0 & 1 \\
\hline
\end{tabular}


Appendix Table 2: Regressions of Probability of Any Generic Entry on Market Size and Controls

\begin{tabular}{|c|c|c|c|c|c|c|c|c|c|c|}
\hline & U.S. & U.K. & Canada & France & Germany & Italy & Spain & Japan & Brazil & Mexico \\
\hline \multirow[t]{2}{*}{ InSales } & 0.003 & $0.028^{\star * *}$ & $0.024^{\star \star \star}$ & $0.020^{\star \star *}$ & $0.043^{\star \star \star}$ & $0.033^{* * *}$ & $0.036^{\star \star *}$ & $0.039^{* * *}$ & $0.055^{\star \star *}$ & 0.008 \\
\hline & [0.005] & {$[0.005]$} & [0.008] & {$[0.004]$} & [0.005] & [0.008] & [0.007] & {$[0.005]$} & [0.009] & [0.007] \\
\hline \multirow[t]{2}{*}{ Licensees } & $-0.061^{*}$ & -0.004 & -0.017 & -0.031 & 0.002 & $-0.040^{* *}$ & 0.032 & 0.022 & 0.020 & 0.022 \\
\hline & {$[0.031]$} & {$[0.027]$} & {$[0.041]$} & [0.019] & {$[0.006]$} & [0.018] & {$[0.031]$} & [0.019] & [0.040] & {$[0.037]$} \\
\hline \multirow[t]{2}{*}{ Orig. forms } & $-0.036^{\star *}$ & 0.010 & -0.011 & $0.027^{* *}$ & $0.029^{* *}$ & -0.015 & 0.029 & $0.071^{* * *}$ & 0.000 & 0.019 \\
\hline & [0.018] & [0.013] & [0.032] & [0.013] & {$[0.014]$} & {$[0.023]$} & [0.033] & {$[0.017]$} & {$[0.036]$} & [0.019] \\
\hline \multirow[t]{2}{*}{ OTC share } & $0.001^{* *}$ & $0.001^{* *}$ & & 0.001 & 0.000 & 0.000 & 0.000 & $-0.002^{\star *}$ & 0.001 & $0.003^{* * *}$ \\
\hline & {$[0.000]$} & {$[0.000]$} & & {$[0.001]$} & {$[0.001]$} & {$[0.002]$} & {$[0.001]$} & {$[0.001]$} & {$[0.001]$} & {$[0.001]$} \\
\hline \multirow[t]{2}{*}{ Hosp. share } & -0.001 & $-0.002^{* * *}$ & $-0.004^{* * *}$ & $-0.001^{*}$ & -0.001 & $-0.003^{* * *}$ & $-0.003^{* *}$ & $-0.001^{*}$ & & \\
\hline & [0.001] & {$[0.000]$} & {$[0.001]$} & {$[0.001]$} & {$[0.001]$} & [0.001] & {$[0.001]$} & {$[0.001]$} & & \\
\hline \multirow[t]{2}{*}{ Ext. release } & $-0.149^{* * *}$ & $-0.123^{\star * *}$ & $-0.219^{\star * *}$ & $-0.088^{\star * *}$ & $-0.134^{* * *}$ & $-0.102^{*}$ & $-0.146^{\star *}$ & -0.053 & $-0.183^{* *}$ & $-0.177^{* * *}$ \\
\hline & {$[0.029]$} & [0.032] & {$[0.035]$} & {$[0.024]$} & [0.039] & {$[0.052]$} & {$[0.065]$} & {$[0.073]$} & {$[0.076]$} & {$[0.040]$} \\
\hline \multirow[t]{2}{*}{ IV form } & -0.031 & -0.001 & $0.203^{*}$ & -0.025 & -0.035 & 0.078 & 0.075 & $-0.112^{* * *}$ & $0.230^{* * *}$ & 0.000 \\
\hline & {$[0.070]$} & {$[0.051]$} & [0.120] & {$[0.046]$} & [0.061] & {$[0.091]$} & [0.113] & [0.038] & [0.058] & [0.052] \\
\hline \multirow[t]{2}{*}{ Topical form } & $-0.183^{* \star *}$ & $-0.180^{* * *}$ & $-0.259^{* * *}$ & $-0.085^{\star *}$ & $-0.197^{* * *}$ & -0.037 & $-0.133^{*}$ & -0.011 & $-0.215^{\star * *}$ & $-0.144^{* * *}$ \\
\hline & [0.029] & [0.018] & [0.027] & {$[0.035]$} & [0.022] & [0.080] & [0.070] & [0.078] & [0.058] & [0.042] \\
\hline \multirow[t]{2}{*}{ Other form } & $-0.161^{* * *}$ & $-0.178^{* * *}$ & $-0.183^{* * *}$ & $-0.113^{* * *}$ & $-0.139^{* * *}$ & -0.014 & -0.036 & $-0.083^{* *}$ & 0.017 & -0.044 \\
\hline & {$[0.028]$} & {$[0.021]$} & {$[0.036]$} & {$[0.021]$} & [0.029] & {$[0.031]$} & {$[0.051]$} & {$[0.033]$} & [0.069] & {$[0.037]$} \\
\hline \multirow[t]{2}{*}{ InGlobalAge } & $0.813^{* * *}$ & $0.640^{* * *}$ & $0.624^{* * *}$ & $0.443^{* * *}$ & $0.604^{* * *}$ & $0.362^{* * *}$ & $0.540^{* * *}$ & $0.617^{* * *}$ & $0.612^{* * *}$ & $0.434^{* * *}$ \\
\hline & {$[0.054]$} & [0.044] & [0.071] & [0.061] & {$[0.050]$} & {$[0.061]$} & {$[0.069]$} & {$[0.057]$} & [0.089] & {$[0.064]$} \\
\hline \multirow[t]{2}{*}{ InMolLag } & $-0.034^{* * *}$ & -0.002 & -0.023 & 0.002 & -0.003 & -0.006 & $-0.041^{*}$ & $-0.015^{*}$ & $-0.066^{* *}$ & $-0.053^{* * *}$ \\
\hline & {$[0.010]$} & [0.008] & {$[0.021]$} & [0.007] & {$[0.010]$} & [0.012] & {$[0.022]$} & [0.009] & [0.028] & [0.018] \\
\hline \multirow[t]{2}{*}{ Global avail. } & -0.002 & 0.017 & -0.034 & 0.034 & 0.050 & 0.016 & $0.147^{* * *}$ & $-0.121^{* * *}$ & $0.141^{* * *}$ & $0.163^{\star * *}$ \\
\hline & {$[0.035]$} & [0.029] & [0.048] & [0.028] & {$[0.037]$} & {$[0.037]$} & [0.049] & {$[0.035]$} & [0.053] & {$[0.036]$} \\
\hline \multirow[t]{2}{*}{ Years 2002-2005 } & $0.114^{* * *}$ & $0.059^{* *}$ & -0.017 & 0.029 & $0.050^{* *}$ & $-0.056^{* * *}$ & $-0.062^{* * *}$ & 0.014 & 0.045 & -0.010 \\
\hline & {$[0.031]$} & {$[0.025]$} & [0.028] & {$[0.025]$} & {$[0.022]$} & {$[0.020]$} & {$[0.023]$} & [0.023] & [0.033] & {$[0.024]$} \\
\hline \multirow[t]{2}{*}{ Years 2006-2009 } & $0.147^{* * *}$ & $0.091^{* * *}$ & -0.008 & $0.097^{* * *}$ & $0.071^{* *}$ & -0.046 & $-0.133^{* * *}$ & 0.046 & -0.043 & -0.012 \\
\hline & {$[0.038]$} & {$[0.032]$} & [0.040] & [0.033] & {$[0.030]$} & {$[0.030]$} & {$[0.034]$} & {$[0.028]$} & [0.047] & {$[0.035]$} \\
\hline $\mathrm{N}$ & 24,572 & 19,554 & 15,713 & 13,296 & 24,390 & 19,881 & 19,481 & 24,690 & 15,804 & 16,437 \\
\hline Pseudo R2 & 0.28 & 0.38 & 0.22 & 0.30 & 0.28 & 0.11 & 0.17 & 0.25 & 0.15 & 0.18 \\
\hline
\end{tabular}


Appendix Table 3: Regressions of No. of Generic Manufacturers on Market Size and Controls

\begin{tabular}{|c|c|c|c|c|c|c|c|c|c|c|}
\hline & U.S. & U.K. & Canada & France & Germany & Italy & Spain & Japan & Brazil & Mexico \\
\hline \multirow[t]{2}{*}{ InSales } & $0.715^{\star \star \star}$ & $0.340^{\star \star *}$ & $0.566^{\star \star \star}$ & $1.588^{* * *}$ & $2.581^{* * *}$ & $0.663^{\star \star \star}$ & $0.981^{\star \star *}$ & $1.825^{\star \star \star}$ & $1.115^{\star \star \star}$ & $0.421^{* * *}$ \\
\hline & {$[0.086]$} & [0.043] & {$[0.100]$} & [0.188] & [0.263] & [0.196] & [0.189] & [0.181] & {$[0.156]$} & [0.079] \\
\hline \multirow[t]{2}{*}{ Licensees } & 0.468 & -0.192 & -0.246 & -0.600 & 0.059 & 0.267 & $1.321^{* *}$ & -0.148 & $0.903^{*}$ & 0.217 \\
\hline & [0.503] & [0.135] & [0.368] & [0.503] & [0.163] & [0.487] & [0.593] & [0.403] & [0.486] & [0.287] \\
\hline \multirow[t]{2}{*}{ Orig. forms } & $-0.548^{* \star *}$ & 0.148 & $-0.583^{* * *}$ & 0.636 & 0.663 & 0.778 & 0.784 & 0.164 & 0.412 & $0.343^{*}$ \\
\hline & [0.205] & [0.115] & [0.221] & {$[0.414]$} & [0.420] & [0.495] & [0.657] & [0.359] & [0.411] & [0.196] \\
\hline \multirow[t]{2}{*}{ OTC share } & $-0.013^{*}$ & -0.001 & & $-0.025^{* *}$ & $0.026^{* * *}$ & -0.002 & $0.040^{* * *}$ & 0.012 & 0.023 & 0.009 \\
\hline & [0.008] & [0.002] & & {$[0.010]$} & {$[0.007]$} & [0.013] & {$[0.010]$} & {$[0.022]$} & [0.016] & [0.012] \\
\hline \multirow[t]{2}{*}{ Hosp. share } & $-0.016^{*}$ & $-0.008^{* *}$ & $-0.045^{* * *}$ & -0.054 & $-0.150^{* * *}$ & -0.031 & -0.027 & $-0.042^{* *}$ & & \\
\hline & [0.009] & {$[0.004]$} & [0.013] & {$[0.036]$} & {$[0.038]$} & {$[0.020]$} & {$[0.028]$} & {$[0.017]$} & & \\
\hline \multirow[t]{2}{*}{ Ext. release } & $-3.291^{* * *}$ & -0.188 & $-1.761^{* * *}$ & -0.704 & -1.009 & $2.432^{* *}$ & $-2.710^{* * *}$ & -0.640 & $-2.354^{* * *}$ & $-1.317^{* * *}$ \\
\hline & [0.289] & [0.365] & [0.396] & [1.329] & [1.484] & [1.142] & [0.865] & [2.306] & [0.316] & [0.185] \\
\hline \multirow[t]{2}{*}{ IV form } & $-2.145^{\star \star *}$ & $-0.637^{\star *}$ & -0.123 & $-3.149^{*}$ & 1.365 & 2.586 & -1.151 & -0.540 & 1.076 & 0.015 \\
\hline & [0.556] & [0.248] & [0.961] & [1.623] & [2.830] & [1.729] & [1.467] & [1.539] & [0.980] & [0.522] \\
\hline \multirow[t]{2}{*}{ Topical form } & $-2.269^{* \star *}$ & $-0.559^{* * *}$ & $-1.606^{* * *}$ & 1.647 & $-8.072^{* * *}$ & $-0.966^{* *}$ & $-2.417^{* * *}$ & $-1.964^{* *}$ & -1.010 & $-1.360^{* * *}$ \\
\hline & [0.655] & {$[0.149]$} & [0.293] & [2.218] & [0.481] & [0.464] & {$[0.900]$} & [0.998] & [1.086] & [0.338] \\
\hline \multirow[t]{2}{*}{ Other form } & $-1.420^{* * *}$ & -0.324 & $-1.630^{* * *}$ & $-2.122^{* *}$ & $-5.745^{\star * \star}$ & -0.723 & $-2.143^{* *}$ & $-1.530^{* *}$ & -0.643 & $-1.264^{* * *}$ \\
\hline & {$[0.474]$} & [0.262] & [0.418] & [0.991] & [0.702] & [0.455] & [0.967] & [0.616] & [0.691] & [0.243] \\
\hline \multirow[t]{2}{*}{ InGlobalAge } & $4.695^{\star * *}$ & $1.582^{* *}$ & $3.218^{* * *}$ & 5.587 & $11.097^{* * *}$ & $4.587^{\star * *}$ & $7.204^{* * *}$ & $2.382^{*}$ & $2.721^{* * *}$ & $2.459^{* * *}$ \\
\hline & [0.999] & [0.615] & [0.887] & [3.711] & [2.913] & [1.395] & [1.757] & [1.395] & [1.048] & [0.822] \\
\hline \multirow[t]{2}{*}{ InMolLag } & $-0.327^{* *}$ & 0.036 & $-0.759^{* * *}$ & -0.359 & -0.207 & -0.357 & $-1.221^{*}$ & 0.031 & $-0.965^{* * *}$ & $-0.489^{* * *}$ \\
\hline & {$[0.149]$} & [0.058] & [0.215] & [0.222] & [0.336] & [0.273] & [0.687] & [0.226] & [0.317] & [0.159] \\
\hline \multirow[t]{2}{*}{ Global avail. } & 0.759 & 0.180 & $0.885^{\star *}$ & 0.903 & $2.594^{* * *}$ & -0.427 & $2.177^{* *}$ & 0.184 & $1.168^{* * *}$ & $1.064^{* * *}$ \\
\hline & [0.546] & {$[0.270]$} & [0.391] & [0.801] & [0.957] & [0.716] & [0.917] & [0.769] & {$[0.426]$} & {$[0.319]$} \\
\hline \multirow[t]{2}{*}{ Years 2002-2005 } & -0.622 & -0.175 & 0.493 & 1.138 & 0.825 & -0.172 & 0.355 & $-1.082^{* * *}$ & $1.332^{* * *}$ & $0.375^{*}$ \\
\hline & {$[0.524]$} & {$[0.345]$} & [0.371] & [1.782] & [0.977] & [0.354] & [0.542] & {$[0.358]$} & [0.313] & [0.223] \\
\hline \multirow[t]{2}{*}{ Years 2006-2009 } & 0.385 & -0.199 & 0.497 & $3.803^{* * *}$ & $2.612^{* *}$ & $1.867^{* *}$ & $1.739^{*}$ & -0.347 & $1.479^{* * *}$ & $0.570^{*}$ \\
\hline & [0.528] & [0.389] & [0.468] & [1.295] & [1.292] & [0.826] & [0.925] & [0.528] & {$[0.500]$} & [0.318] \\
\hline $\mathrm{N}$ & 5,665 & 3,580 & 4,137 & 1,544 & 5,203 & 3,290 & 5,775 & 5,962 & 6,115 & 3,726 \\
\hline
\end{tabular}

Marginal effects from Negative-Binomial regressions, clustered by molecule; robust standard errors in brackets, significant at ${ }^{* \star *} \mathrm{p}<0.01$, ${ }^{* *} p<0.05,{ }^{*} p<0.10$

Appendix Table 4: Regressions of Normalized Generic Prices on No. of Generic Manufacturers and Controls

\begin{tabular}{|c|c|c|c|c|c|c|c|c|c|c|}
\hline & U.S. & U.K. & Canada & France & Germany & Italy & Spain & Japan & Brazil & Mexico \\
\hline \multirow[t]{2}{*}{ GenMfrBrand } & 0.029 & $-0.097^{* * *}$ & $-0.014^{* *}$ & -0.014 & $-0.009^{* *}$ & 0.002 & -0.006 & $-0.010^{* * *}$ & $-0.006^{* *}$ & $0.038^{*}$ \\
\hline & {$[0.043]$} & [0.033] & {$[0.005]$} & {$[0.009]$} & [0.004] & [0.004] & [0.004] & {$[0.002]$} & [0.002] & {$[0.020]$} \\
\hline \multirow[t]{2}{*}{ GenMfrUnbr. } & $-0.043^{* * *}$ & $-0.076^{* * *}$ & $-0.011^{* *}$ & -0.006 & $-0.015^{\star * *}$ & $-0.043^{* * *}$ & $-0.013^{* * *}$ & 0.001 & $-0.012^{* *}$ & $-0.080^{* *}$ \\
\hline & [0.005] & {$[0.014]$} & {$[0.005]$} & [0.004] & {$[0.003]$} & {$[0.006]$} & [0.002] & [0.002] & [0.005] & {$[0.037]$} \\
\hline \multirow[t]{2}{*}{ Ext. release } & 0.084 & $0.224^{* * *}$ & $0.074^{* *}$ & -0.019 & 0.031 & 0.036 & $0.142^{* * *}$ & -0.047 & 0.041 & $0.383^{* * *}$ \\
\hline & {$[0.067]$} & {$[0.074]$} & {$[0.029]$} & {$[0.020]$} & [0.033] & [0.043] & [0.033] & {$[0.034]$} & [0.051] & {$[0.087]$} \\
\hline \multirow[t]{2}{*}{ IV form } & -0.099 & $0.140^{* * *}$ & 0.027 & $-0.138^{\star *}$ & $0.240^{* * *}$ & -0.074 & -0.028 & $0.126^{* * *}$ & $0.052^{*}$ & $-0.094^{*}$ \\
\hline & [0.070] & [0.048] & [0.042] & {$[0.057]$} & [0.043] & [0.073] & {$[0.040]$} & [0.033] & [0.029] & [0.055] \\
\hline \multirow[t]{2}{*}{ Topical form } & $0.200^{* *}$ & $0.278^{* * *}$ & 0.016 & $0.343^{* * *}$ & $0.115^{\star *}$ & -0.069 & $0.069^{* * *}$ & $0.112^{* *}$ & $0.222^{* *}$ & 0.061 \\
\hline & [0.089] & [0.040] & [0.038] & [0.039] & {$[0.050]$} & {$[0.051]$} & [0.025] & [0.049] & [0.094] & [0.086] \\
\hline \multirow[t]{2}{*}{ Other form } & 0.076 & $0.178^{* *}$ & -0.060 & $-0.061^{* *}$ & $0.198^{* * *}$ & $0.063^{*}$ & 0.058 & $0.165^{\star * *}$ & $0.071^{* *}$ & 0.070 \\
\hline & [0.072] & [0.068] & [0.040] & {$[0.027]$} & {$[0.075]$} & {$[0.034]$} & [0.035] & {$[0.034]$} & {$[0.030]$} & {$[0.079]$} \\
\hline \multirow[t]{2}{*}{ InGlobalAge } & -0.156 & $-0.542^{* * *}$ & 0.060 & 0.026 & $-0.385^{* * *}$ & -0.003 & $-0.200^{* * *}$ & $-0.353^{* * *}$ & -0.059 & $-0.215^{\star}$ \\
\hline & [0.109] & {$[0.115]$} & {$[0.057]$} & [0.046] & {$[0.066]$} & [0.074] & [0.052] & [0.064] & {$[0.050]$} & {$[0.117]$} \\
\hline \multirow[t]{2}{*}{ InMolLag } & 0.013 & $0.029^{*}$ & -0.013 & -0.002 & 0.021 & -0.014 & 0.016 & 0.001 & 0.016 & -0.028 \\
\hline & [0.015] & [0.015] & {$[0.011]$} & [0.008] & [0.013] & {$[0.014]$} & [0.012] & {$[0.006]$} & {$[0.014]$} & {$[0.026]$} \\
\hline \multirow[t]{2}{*}{ Global avail. } & 0.015 & -0.079 & 0.033 & 0.000 & 0.005 & 0.009 & $-0.056^{\star * *}$ & $0.068^{* * *}$ & $-0.084^{\star * *}$ & -0.016 \\
\hline & {$[0.042]$} & {$[0.048]$} & {$[0.028]$} & {$[0.033]$} & {$[0.040]$} & [0.044] & {$[0.021]$} & {$[0.024]$} & {$[0.025]$} & [0.055] \\
\hline \multirow[t]{2}{*}{ Years 2002-2005 } & 0.011 & $-0.097^{* * *}$ & $-0.055^{\star *}$ & $-0.040^{*}$ & -0.026 & $-0.126^{\star * *}$ & $-0.114^{* * *}$ & $-0.049^{* * *}$ & $-0.246^{\star \star *}$ & -0.058 \\
\hline & {$[0.036]$} & {$[0.031]$} & {$[0.027]$} & {$[0.023]$} & [0.029] & [0.023] & {$[0.018]$} & [0.017] & {$[0.017]$} & {$[0.041]$} \\
\hline \multirow[t]{2}{*}{ Years 2006-2009 } & 0.011 & $-0.331^{* * *}$ & $-0.092^{* * *}$ & $-0.250^{\star \star *}$ & $-0.151^{* \star *}$ & $-0.298^{* * *}$ & $-0.277^{* * *}$ & $-0.128^{* * *}$ & $-0.273^{* \star *}$ & $-0.129^{* *}$ \\
\hline & {$[0.043]$} & {$[0.045]$} & [0.031] & {$[0.034]$} & [0.042] & [0.032] & {$[0.023]$} & {$[0.023]$} & {$[0.027]$} & {$[0.056]$} \\
\hline $\mathrm{N}$ & 5,097 & 3,369 & 3,820 & 1,522 & 4,768 & 2,922 & 5,236 & 5,672 & 4,671 & 2,814 \\
\hline R-squared & 0.32 & 0.44 & 0.10 & 0.55 & 0.54 & 0.62 & 0.67 & 0.35 & 0.54 & 0.15 \\
\hline
\end{tabular}


Appendix Table 5: Regressions of Generic Share of Volume on Normalized Generic Price, No. of Generic Manufacturers and Controls

\begin{tabular}{|c|c|c|c|c|c|c|c|c|c|c|}
\hline & U.S. & U.K. & Canada & France & Germany & Italy & Spain & Japan & Brazil & Mexico \\
\hline \multirow[t]{2}{*}{ GenPrice } & $-0.144^{\star * *}$ & $-0.228^{* * *}$ & $-0.382^{\star \star \star}$ & $-0.262^{*}$ & $-0.202^{* *}$ & 0.039 & -0.068 & 0.050 & $-0.346^{* * *}$ & $0.140^{\star *}$ \\
\hline & [0.039] & [0.053] & [0.115] & [0.135] & [0.083] & {$[0.165]$} & [0.124] & [0.093] & [0.102] & [0.068] \\
\hline \multirow[t]{2}{*}{ GenMfrBrand } & 0.022 & $0.063^{*}$ & $0.031^{* * *}$ & 0.017 & $0.010^{*}$ & -0.004 & $0.030^{* * *}$ & $0.005^{\star *}$ & $0.011^{* * *}$ & $0.026^{* * *}$ \\
\hline & [0.023] & [0.033] & [0.010] & [0.016] & [0.006] & [0.009] & {$[0.007]$} & {$[0.002]$} & {$[0.004]$} & [0.009] \\
\hline \multirow[t]{2}{*}{ GenMfrUnbr. } & $0.009^{* * *}$ & $0.095^{\star * *}$ & $0.036^{* * *}$ & $0.035^{\star * *}$ & $0.019 * * *$ & 0.021 & $0.007^{* *}$ & $0.003^{*}$ & $0.023^{* * *}$ & 0.008 \\
\hline & [0.003] & [0.020] & {$[0.010]$} & {$[0.007]$} & [0.003] & {$[0.014]$} & {$[0.003]$} & [0.002] & [0.007] & {$[0.020]$} \\
\hline \multirow[t]{2}{*}{ Ext. release } & $-0.087^{*}$ & -0.070 & $0.109^{*}$ & 0.052 & -0.043 & 0.183 & -0.086 & 0.131 & -0.093 & -0.051 \\
\hline & {$[0.044]$} & [0.069] & [0.061] & {$[0.047]$} & [0.092] & {$[0.136]$} & [0.115] & [0.138] & [0.099] & [0.066] \\
\hline \multirow[t]{2}{*}{ IV form } & $-0.174^{* \star *}$ & $-0.279^{* * *}$ & 0.040 & -0.161 & 0.079 & 0.153 & 0.001 & $0.148^{* * *}$ & -0.086 & -0.048 \\
\hline & {$[0.034]$} & [0.105] & [0.068] & [0.169] & {$[0.084]$} & {$[0.100]$} & {$[0.097]$} & {$[0.040]$} & {$[0.056]$} & {$[0.078]$} \\
\hline \multirow[t]{2}{*}{ Topical form } & 0.017 & $-0.156^{* * *}$ & 0.023 & & $-0.151^{* * *}$ & 0.091 & -0.003 & 0.019 & $-0.211^{* * *}$ & 0.068 \\
\hline & {$[0.032]$} & [0.041] & {$[0.076]$} & & {$[0.046]$} & {$[0.084]$} & [0.218] & {$[0.022]$} & {$[0.057]$} & {$[0.083]$} \\
\hline \multirow[t]{2}{*}{ Other form } & -0.046 & $-0.239^{* * *}$ & 0.056 & $-0.187^{\star * *}$ & 0.075 & 0.088 & 0.001 & $0.131^{\star * *}$ & -0.048 & -0.006 \\
\hline & {$[0.037]$} & {$[0.041]$} & [0.055] & {$[0.062]$} & {$[0.057]$} & [0.077] & [0.060] & [0.048] & [0.063] & [0.070] \\
\hline \multirow[t]{2}{*}{ InGlobalAge } & 0.056 & 0.142 & 0.099 & 0.040 & -0.076 & 0.137 & -0.006 & -0.149 & $-0.237^{* *}$ & 0.116 \\
\hline & {$[0.060]$} & [0.114] & [0.069] & [0.102] & [0.101] & [0.152] & [0.110] & [0.104] & {$[0.100]$} & [0.110] \\
\hline \multirow[t]{2}{*}{ InMolLag } & $0.012^{*}$ & -0.014 & -0.024 & -0.003 & $0.021^{*}$ & 0.012 & -0.011 & 0.000 & $0.099^{* *}$ & 0.010 \\
\hline & [0.007] & [0.015] & {$[0.015]$} & {$[0.018]$} & {$[0.011]$} & {$[0.023]$} & {$[0.034]$} & [0.005] & [0.038] & {$[0.026]$} \\
\hline \multirow[t]{2}{*}{ InGenAge } & $0.091^{* * *}$ & $0.092^{* * *}$ & $0.077^{* * *}$ & $0.102^{* * *}$ & $0.115^{\star * *}$ & 0.041 & $0.099^{* * *}$ & $0.042^{* * *}$ & $0.140^{* * *}$ & $0.090^{* * *}$ \\
\hline & [0.011] & [0.016] & [0.020] & [0.013] & [0.015] & {$[0.030]$} & [0.016] & {$[0.014]$} & [0.021] & {$[0.024]$} \\
\hline \multirow[t]{2}{*}{ Global avail. } & $-0.037^{*}$ & 0.000 & 0.047 & -0.039 & 0.018 & -0.101 & -0.040 & 0.038 & 0.015 & -0.004 \\
\hline & {$[0.021]$} & {$[0.048]$} & [0.044] & [0.033] & {$[0.032]$} & [0.064] & [0.048] & {$[0.027]$} & [0.049] & [0.060] \\
\hline \multirow[t]{2}{*}{ Years 2002-2005 } & $0.136^{\star * \star}$ & $0.177^{\star * *}$ & 0.032 & 0.039 & 0.036 & 0.030 & 0.002 & $0.028^{*}$ & $0.065^{*}$ & 0.051 \\
\hline & {$[0.027]$} & {$[0.056]$} & {$[0.031]$} & {$[0.041]$} & [0.033] & {$[0.056]$} & [0.035] & [0.015] & {$[0.036]$} & [0.038] \\
\hline \multirow[t]{2}{*}{ Years 2006-2009 } & $0.182^{* * *}$ & $0.155^{\star \star *}$ & 0.010 & $0.188^{* * *}$ & 0.001 & -0.046 & -0.021 & $0.033^{*}$ & $0.181^{* * *}$ & 0.070 \\
\hline & {$[0.027]$} & [0.059] & {$[0.033]$} & {$[0.044]$} & {$[0.049]$} & {$[0.078]$} & {$[0.050]$} & [0.019] & {$[0.052]$} & {$[0.050]$} \\
\hline $\mathrm{N}$ & 5,097 & 3,369 & 3,680 & 1,514 & 4,566 & 2,922 & 5,236 & 5,385 & 4,671 & 2,814 \\
\hline R-squared & 0.47 & 0.57 & 0.35 & 0.68 & 0.52 & 0.15 & 0.31 & 0.13 & 0.45 & 0.25 \\
\hline
\end{tabular}

